\title{
Mechanical Characterization of Low Permeable Siltstone under Different Reservoir Saturation Conditions: An Experimental Study
}

\author{
Ayal Wanniarachchi ${ }^{1}$ D , Ranjith Pathegama Gamage ${ }^{1}\left(\mathbb{D}\right.$, Qiao Lyu $^{2, *}$, Samintha Perera ${ }^{1,3} \mathbb{D}^{\text {, }}$ \\ Hiruni Wickramarathne ${ }^{1}$ and Tharaka Rathnaweera ${ }^{1}$ (D) \\ 1 Deep Earth Energy Laboratory, Department of Civil Engineering, Monash University, Building 60, \\ Melbourne 3800, Australia; ayal.maneth@monash.edu (A.W.); ranjith.pg@monash.edu (R.P.G.); \\ samintha.perera@unimelb.edu.au (S.P.); mhde2@student.monash.edu (H.W.); \\ tharaka.rathnaweera@monash.edu (T.R.) \\ 2 School of Geosciences and Info-physics, Central South University, Changsha 410012, China \\ 3 Department of Infrastructure Engineering, The University of Melbourne, Building 175, \\ Melbourne 3010, Australia \\ * Correspondence: lvqiao@csu.edu.cn
}

Received: 27 November 2018; Accepted: 18 December 2018; Published: 21 December 2018

\begin{abstract}
Hydro-fracturing is a common production enhancement technique used in unconventional reservoirs. However, an effective fracturing process requires a precise understanding of a formation's in-situ strength behavior, which is mainly dependent on the formation's in-situ stresses and fluid saturation. The aim of this study is to identify the effect of brine saturation (concentration and degree of saturation (DOS)) on the mechanical properties of one of the common unconventional reservoir rock types, siltstone. Most common type of non-destructive test: acoustic emission (AE) was used in conjunction with the destructive tests to investigate the rock properties. Unconfined compressive strength (UCS) and splitting tensile strength (STS) experiments were carried out for 78 varyingly saturated specimens utilizing ARAMIS (non-contact and material independent measuring system) and acoustic emission systems to determine the fracture propagation. According to the experimental results, the increase in degree of pore fluid saturation ( $\mathrm{NaCl}$ ionic solution) causes siltstone's compressive and tensile strengths to be reduced through weakening and breakage of the existing bonding between clay minerals. However, increasing $\mathrm{NaCl}$ concentration in the pore fluid generally enhances the compressive strength of siltstone through associated $\mathrm{NaCl}$ crystallization effect and actually reduces the tensile strength of siltstone through the corrosive influence of the $\mathrm{NaCl}$ ions. Moreover, results show that AE capture and analysis is one of the most effective methods to understand crack propagation behavior in rocks including the crack initiation, crack propagation, and final failure. The findings of this study are important for the identification of fluid saturation dependent in-situ strength conditions for successful hydro-fracturing in low permeable reservoirs.
\end{abstract}

Keywords: hydro-fracturing; siltstone; compressive strength; tensile strength; brine; stress-strain; acoustic emission

\section{Introduction}

The rapid depletion of conventional energy resources is one of the major problems the world faces today, particularly given the continuously increasing energy consumption. Extensive research on potential new energy resources and production-enhancement techniques has therefore been initiated worldwide to effectively face this energy crises [1-3], and natural gas extraction is one effective solution. Although the extraction of conventional natural gas is generally much cheaper 
compared to unconventional gas [4], the amount of conventional gas available is quite limited. Therefore, unconventional natural gas extraction is becoming necessary. Recent advances in the petroleum industry, such as horizontal well drilling and hydro-fracturing, have significantly improved unconventional natural gas production from deep geological formations [5-11], particularly in countries such as the U.S., China, Canada, and Germany. Of the various reservoir productivityenhancement techniques, hydro-fracturing is dominant and has been widely used. This fracturing process involves a number of steps: vertical well drilling, horizontal well drilling, injection of fracturing fluid, and fluid flow-back and gas production via the drilled production wells. Of these, the injection of fracturing fluid plays a major role in enhancing reservoir productivity. Although water with added chemicals is commonly used as the fracturing fluid, non-water-based fracturing fluids and gases $\left(\mathrm{CO}_{2}\right.$, $\mathrm{N}_{2}$ ), foams, energized fluids, alcohols, and acids have also recently been tested in the field [12].

The creation of hydro-fractures in deep geological formations using any of these fracturing fluids depends on both the formation properties and the injection conditions of the fracturing fluid, including overburden stress, confinement, rock strength and composition, available pore fluids (water, brine, oil etc.), degree of saturation in the aquifer, and fracture fluid injection pressure [13-17]. According to existing research, with fracture fluid injection, fractures normally occur in the formation rock in a perpendicular direction to the minimum stress and failure can occur as tensile, shear or compression failure. However, it should be noted that rocks are generally highly brittle materials and therefore have much lower tensile strength than compressive strength (tensile strength is less than $10 \%$ of compressive strength). As a result, fractures are more likely to occur through tensile failure or shear failure or a combination of the two (hybrid failure). The strength of any reservoir rock depends on many other factors, including temperature, confining pressure (depth), mineral composition, pore size distribution, porosity, and degree of saturation [18-24] and the evaluation of the effect of strength is therefore a complex matter. On the other hand, in order to fracture formation rocks that exist under high confinements due to the greater depths of unconfined gas reservoirs, it is necessary to have higher injection pressure, because rock failure occurs only when the applied pressure goes beyond the effective stress applying on it (a negative effective stress condition).

Apart from the reservoir rocks' strength parameters, pore fluid concentration and its degree of saturation in the aquifer rock also play major roles in the hydro-fracturing process in deep unconfined gas reservoirs, because they indirectly affect the rock mechanical properties. With the injection of the fracturing fluid into a saturated (by water, brine, or oil) geological formation, the degree of water/brine/oil saturation around the injection well starts to decrease due to the forced migration caused by the fracturing fluid. This is depending on the injection pressure of the fracturing fluid and the ability of that fracturing fluid to move through the reservoir rock (its permeability) [25]. This pushing out of pore fluid (the forced migration) through the injecting fluid can have the effect of totally removing pore fluid from the well bore area. This pore fluid pushing influence reduces with increasing distance from the injection well due to the reduced pressure created by the injecting fluid on the pore fluid. Moreover, all of these pore fluid replacement processes through the injection fluid depend on the pore pressure of the fluid. Deep aquifers normally have greater pore pressure and therefore, the influence of the injecting fluid is less than in shallow aquifers [26,27]. Moreover, it should be noted that initiation and propagation of the primary hydraulic fracture have to be occurred very quickly for a minimal fluid leakoff, because it may demand high pumping rates. The situation is however different for the occurring secondary fractures, where initiation and propagation of them should be taken place over some considerable time duration to allow the fracturing fluid to leak into the reservoir rock. Therefore, the change of degree of saturation and its concentration has a direct influence on the rock mechanical properties, which therefore vary over time during the fracturing process, affecting the fracturing pressure required for hydro-fractures to be initiated.

To date, many studies have therefore been performed to identify the effect of brine saturation (the salinity effect) on the strength of reservoir rocks, including sandstone, siltstone and limestone [25,28-31]. The studies have found a clear influence of brine saturation on reservoir 
rock mechanical properties, including rock strength gain under certain circumstances, due to $\mathrm{NaCl}$ crystallization inside the rock pores. Although $\mathrm{NaCl}$ crystallization enhances rock strength by creating additional bonds between solid particles, brine saturation may cause the rock to be corroded by reducing its strength due to its high ionic strength [29]. Reservoir rock strength is therefore dependent on the dominant factor under each saturation condition. For example, according to Shukla, Ranjith [26], rock strength is highly dependent on the $\mathrm{NaCl}$ concentration, and it initially reduces, and then increases with increasing $\mathrm{NaCl}$ concentration. Although brine has some ability to enhance reservoir rock strength through $\mathrm{NaCl}$ crystallization, overall the saturation of any rock with brine causes it to soften in the wetting phase, reducing its strength, although this strength reduction can be reduced by the existence of ions in the saturation fluid. For example, rock strength reduction under water saturation is higher than the strength reduction which occurs under brine saturation, although both saturations reduce the rock strength.

A number of studies to date have identified the effects of this fluid saturation and concentration on the mechanical properties of aquifer rock. However, most previous studies have been performed on sandstone and geo-polymer specimens, and only the effects of brine concentration/degree of saturation have been considered and the studies have been limited to unconfined compression strength (UCS) tests. However, as mentioned earlier, hydro-fractures are mainly initiated by the tensile failure of the rock due to the much lower tensile strengths of brittle rocks compared to their compressive strengths. The evaluation of the effect of saturation on rock tensile strength is therefore far more important than checking its influence on compressive strength for the hydro-fracturing process. Although siltstone is a common rock type in many unconventional reservoirs, to date little research has been conducted on strength variation with formation properties such as $\mathrm{NaCl}$ ionic concentration, composition and saturation, where the pore fluid is mainly composed of $\mathrm{NaCl}$ [29]. This paper therefore reports on a strength study of varyingly brine $(\mathrm{NaCl})$ saturated siltstone.

\section{Experimental methodology}

\subsection{Rock Specimens}

Eidsvold siltstones formed in the Triassic, Jurassic, and Cretaceous periods were collected from the Eidsvold (Burnett Highway) basin outcrop in Queensland, Australia (Figure 1a). Based on electron microscope (SEM) observations, this particular type of siltstone is nearly homogeneous with 0.01-0.05 mm grain size distribution. According to X-ray diffraction (XRD) (Bruker D8 Cobalt Bruker, Massachusetts, MA, United States) analysis, this siltstone is basically composed of quartz and kaolinite minerals (43\% and $40 \%$ of quartz and kaolinite, respectively). Apart from these major minerals, it also has around $12 \%$ of tridymite, $3 \%$ of mica, $1 \%$ of anatase, $1 \%$ of other clay minerals and negligible amount of organic matter. Figure 1a-b show SEM and computed tomography (CT) scanning images of a typical Eidsvold siltstone specimen. As can be seen from Figure 1b, this siltstone has randomly distributed pore voids with an average size of around $800 \mathrm{~nm}$ and according to Figure 1c, the pore voids are different in size and randomly distributed throughout the rock. Importantly, Figure 1c illustrates how the pore voids in this siltstone connect to each other along the height of the specimen, creating a pore network, which significantly affects its mechanical properties, including strength, elastic modulus and Poisson's ratio. 


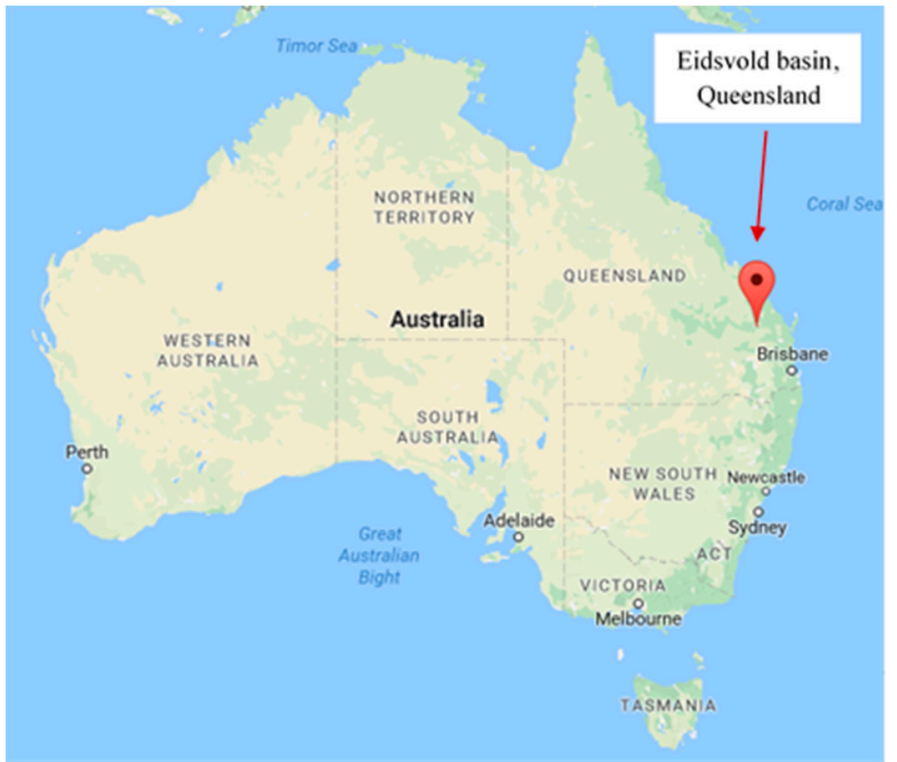

(a)

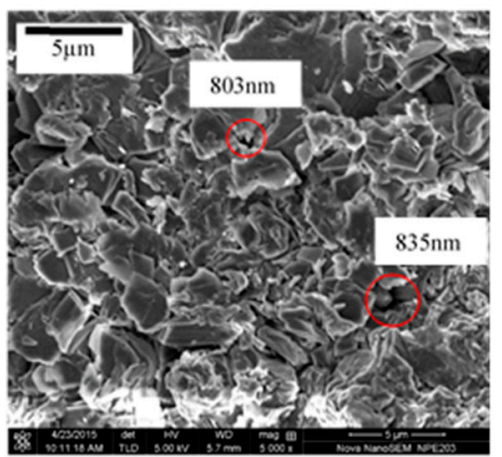

(b)

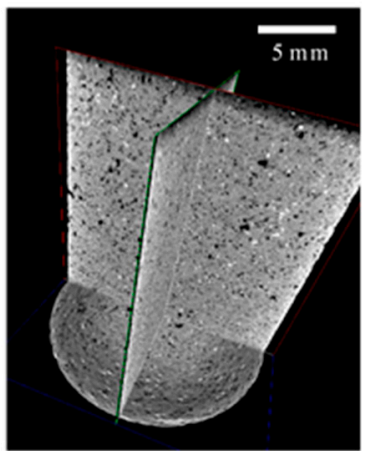

(c)

Figure 1. (a) Location of the Eidsvold basin (specimen location); (b) SEM analysis image of siltstone with pore size; (c) computed tomography (CT) scanning image with internal pore network.

\subsection{Specimen Preparation}

The collected siltstone blocks were first cored into $38 \mathrm{~mm}$ diameter specimens using the diamond coring machine available in the Monash University Deep Earth Energy Research Laboratory (DEERL) using water as a lubricant (to minimize the chemical reactions), and then cut into two heights, $76 \mathrm{~mm}$ and $19 \mathrm{~mm}$, using the diamond cutting machine, for the UCS tests and splitting tensile strength (STS) tests, respectively. The surfaces of the specimens were then ground using the diamond grinding machine available in the DEERL to comply with the ASTM D3967 standard. All the specimens were stored in an oven at $70^{\circ} \mathrm{C}$ for 4 days to remove moisture from the specimens. The low temperature condition of $70^{\circ} \mathrm{C}$ was used to avoid any thermal cracks.

\subsection{Specimen Saturation}

The oven-dried specimens were removed from the oven, weighed and then allowed to cool for 6 hours. $10 \%, 20 \%$, and $25 \%$ by weight $\mathrm{NaCl}$ brine solutions were then prepared and initially three UCS test specimens $(38 \times 76 \mathrm{~mm})$ and three STS test specimens $(38 \times 19 \mathrm{~mm})$ were fully immersed in each brine solution. Vacuum desiccators were used to saturate the specimens by removing the air from the specimens. Specimen weights were measured over time to monitor the saturation process until the weights became constant. When the weight became constant, that saturation level was considered fully saturated or $100 \%$ degree of saturation (DOS). The weight of absorbed water at the $100 \%$ DOS 
was calculated for both types of specimens and the water content for $25 \%, 50 \%$, and $75 \%$ DOS was calculated. Three UCS specimens were then fully immersed in each brine solution and the weight was measured from time to time until it achieved the water content required to achieve $25 \%$ DOS. The same procedure was repeated for other DOS levels (50\% and 75\%) and for the STS test specimens. The saturated specimens were then fully covered with polythene and stored in a fog room for one month to equally distribute the brine throughout the specimen without evaporating the brine in the specimen.

\subsection{Testing Procedure}

Three oven-dried specimens and 36 saturated specimens were selected for each UCS and STS test. All the specimens were painted in a stochastic pattern using two colors (black dots on white background) to enable the ARAMIS camera to capture images of specimen failure during loading. ARAMIS is a non-contact and material-independent measuring system with hardware and software components developed by GOM, Brunswick, Germany, which has the capability to measure 3-D surface coordinates and surface strain values using two 5 megapixels 3.45 micron pitch cameras. An advanced acoustic emission (AE) system was used to identify crack propagation and energy release during UCS loading. Here, a passive $\mathrm{AE}$ technique was used to acquire the $\mathrm{AE}$ data, in which measurements are taken during the loading. Two AE sensors were attached to the top and bottom platens of the loading machine to capture the AE signals. A Shimadzu uniaxial testing machine was used for both the UCS and STS tests, which is capable of applying a maximum axial load of $300 \mathrm{kN}$. A $0.1 \mathrm{~mm} / \mathrm{min}$ strain rate was selected to fail the specimens within 5-15 min, according to the ASTM standards. The Shimadzu machine, data logger, AE system and ARAMIS camera (Figure 2) were started simultaneously to start the experiment and three specimens were tested for each DOS and brine concentration. The UCS, elastic modulus and Poisson's ratio of the UCS specimens were calculated using the stress-strain diagram for each specimen and the splitting tensile strength was then calculated using Equation (1) [32].

$$
\sigma_{\mathrm{t}}=\frac{2 \mathrm{P}}{\pi \mathrm{LD}}
$$

where, $\sigma_{t}$ is the splitting tensile strength, $\mathrm{P}$ is the maximum applied load indicated by the testing machine, $\mathrm{L}$ is the thickness of the specimen and $\mathrm{D}$ is the diameter of the specimen.

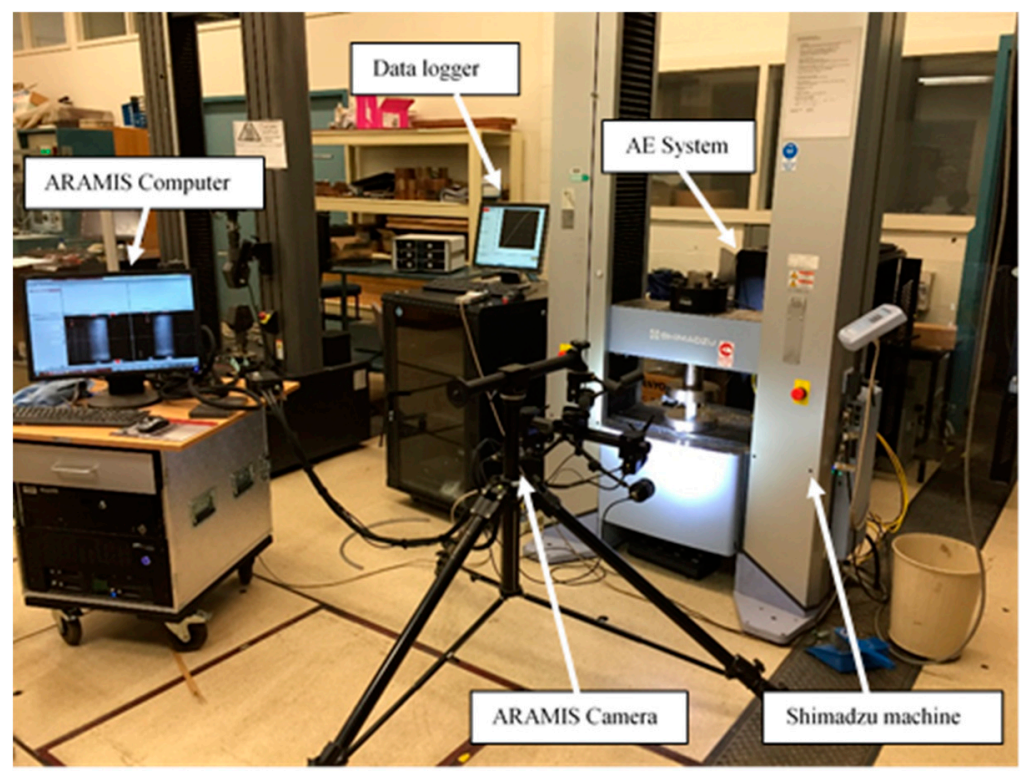

Figure 2. Shimadzu testing machine with ARAMIS (non-contact and material independent measuring system) and acoustic emission (AE) system. 


\section{Results and Discussion}

The degrees of brine saturation variation (calculated based on the accumulated weight over the time with respect to the $100 \%$ saturated specimen weight) over time in the specimens for UCS and STS tests for the three $\mathrm{NaCl}$ concentration conditions considered are shown in Figure 3. As the figure shows, the degree of saturation is clearly dependent on the concentration of the $\mathrm{NaCl}$, and increasing the $\mathrm{NaCl}$ concentration from $10 \%$ to $25 \%$ causes the time required to achieve a certain degree of saturation to be reduced. This is related to the lower ionic potential of the low concentration $\mathrm{NaCl}$ that leads to a slower chemical interaction with the rock. However, after sufficient time (10 days in the present study), the degree of saturation becomes similar for all $\mathrm{NaCl}$ concentration conditions. The effect of this $\mathrm{NaCl}$ saturation at various degrees of saturation and at various concentrations on both the compressive and tensile strength of siltstone was then investigated and the results are discussed in the following sections.

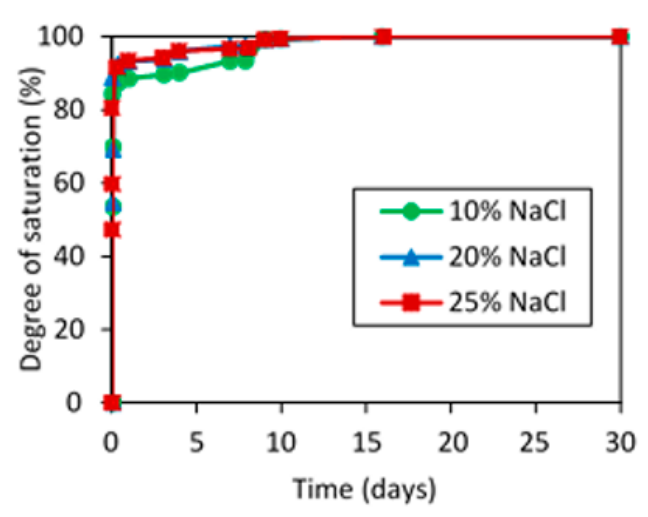

(a)

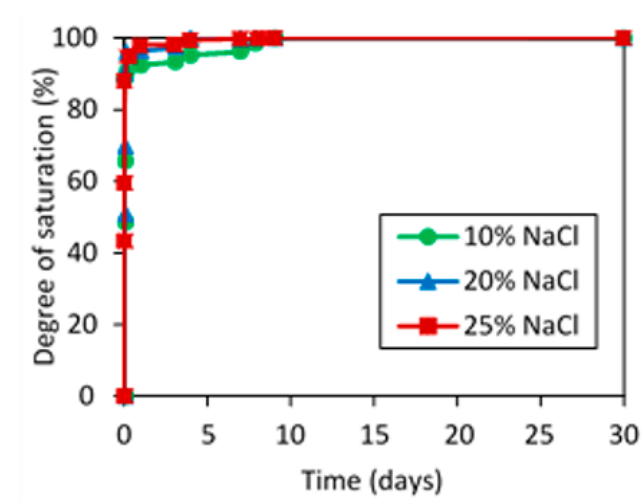

(b)

Figure 3. Variation of degree of saturation over time in specimens prepared for (a) unconfined compressive strength (UCS); (b) splitting tensile strength (STS) tests for varying concentrations of brine $(10 \%, 20 \%, 25 \% \mathrm{NaCl})$.

\subsection{Compressive Strength of Siltstone Under Different Fluid Saturation Conditions}

The variations of unconfined compressive strength (UCS) of siltstone with $\mathrm{NaCl}$ ionic concentration and degree of saturation were first checked and the results are shown in Figure 4. Note that triplicate specimens were tested for each $\mathrm{NaCl}$ concentration and $\mathrm{DOS}$ and the average value was considered as the UCS value for a particular saturation condition. Table 1 shows the UCS values for each tested specimen with the average values as well as the standard deviations. According to Figure 4 and Table 1, the UCS of the tested siltstone varies from $37.7 \mathrm{MPa}$ to $61.6 \mathrm{MPa}$, depending on the $\mathrm{NaCl}$ ionic solution saturation condition. The maximum strength of around $61.6 \mathrm{MPa}$ can be seen for the $0 \% \mathrm{DOS}$ (dry) specimen and any type of $\mathrm{NaCl}$ ionic solution causes that strength to be reduced. This is due to the water softening effect, through which water molecules weaken the clay mineral and rock bonding, resulting in reduced overall strength in the rock [33-35]. Further, the attachment of water molecules to rock particles breaks the solid-solid bonds by creating new solid-liquid bonds, which are much weaker than solid-solid bonds. As a result, the increasing number of such bonds causes the rock overall strength to be reduced. Moreover, since the tested siltstone has high quartz content $(43 \%)$, pore fluid saturation replace the existing $\mathrm{Si}-\mathrm{O}-\mathrm{Si}$ bonds with $\mathrm{Si}-\mathrm{OH}-\mathrm{OH}-\mathrm{Si}$ with creating a deficiency to the quartz mineral structure, which in turn promotes the crack initiation through weakening the crack tips [36]. This also contribute to reduce the mechanical properties of rock upon pore fluid saturation. Furthermore, adsorption of $\mathrm{H}^{+}$ions into the negatively charged clay minerals in the rock also contribute to the weakening of the rock through expanding the clay layers [37]. According to Figure 4, a comparison of all the brine- saturated specimens indicates that the $10 \% \mathrm{NaCl}$-saturated specimens exhibit the lowest UCS values and the $20 \% \mathrm{NaCl}$-saturated specimens exhibit the highest 
UCS values under any degree of saturation condition. The specimens saturated with the highest $\mathrm{NaCl}$ concentration (i.e., $25 \% \mathrm{NaCl}$ ) exhibit strength values between these figures. According to the strength classification of intact and jointed rocks (Table 2), dry specimens can be classified as class $\mathrm{C}$ (moderate strength). All the DOS levels (i.e., $25 \%, 50 \%, 75 \%$, and $100 \%$ ) in $10 \%$ and $25 \% \mathrm{NaCl}$ can be classified as class D (medium strength). However, in $20 \% \mathrm{NaCl}, 25 \%$ and $50 \%$ DOS levels, specimens belong to class C (moderate strength) and 75\% and 100\% DOS levels, specimens belong to the class D (medium strength). However, the class C classification is marginal for $20 \% \mathrm{NaCl}$ specimens and they can also be classified as class D. Increasing siltstone strength with increasing brine concentration is related to the $\mathrm{NaCl}$ crystallization effect, as the formation of $\mathrm{NaCl}$ crystals in rock pores can offer an added strength to the rock. This can be confirmed by using the SEM images of the saturated and dry siltstone specimens (Figure 5). This has been observed in other types of rocks such as sandstone and geo-polymer in the research literature and seems to be applicable to siltstone $[29,30]$. On the other hand, $\mathrm{NaCl}$ solution reduces the diffusion double layer (DDL) of the existing clay minerals in near minerals surface that in turn weaken the rock [38,39]. Furthermore, as mentioned earlier, ionic concentrations can have a corrosive influence on reservoir rock by reducing its strength $[40,41]$, and this may also reduce the UCS strength characteristics at very high $\mathrm{NaCl}$ concentrations $(25 \% \mathrm{NaCl}$ concentration here). This also can be seen in the Figure 5, where at $25 \% \mathrm{NaCl}$ concentration, some areas of the rock matrix have corroded by reducing the overall strength of the siltstone. According to the results, it can be concluded that when siltstone is saturated with $10 \% \mathrm{NaCl}$ concentration, the ionic strength of the $\mathrm{NaCl}$ ionic solution is not sufficient to have any influence on siltstone strength. The strength of the rock is reduced mainly due to the quartz mineral dissolution and softening effect created by the wetting phase (water) molecules in the pore fluid, and increasing the concentration of $\mathrm{NaCl}$ ionic solution to $20 \%$ causes the creation of a considerable number of $\mathrm{NaCl}$ crystals among the pores in the rock. Although further increasing the $\mathrm{NaCl}$ concentration causes the crystallization processes to accelerate, the simultaneously increasing ionic corrosion and clay minerals' diffusion double layer reduction effects goes beyond the crystallization effect at $25 \% \mathrm{NaCl}$ concentration.

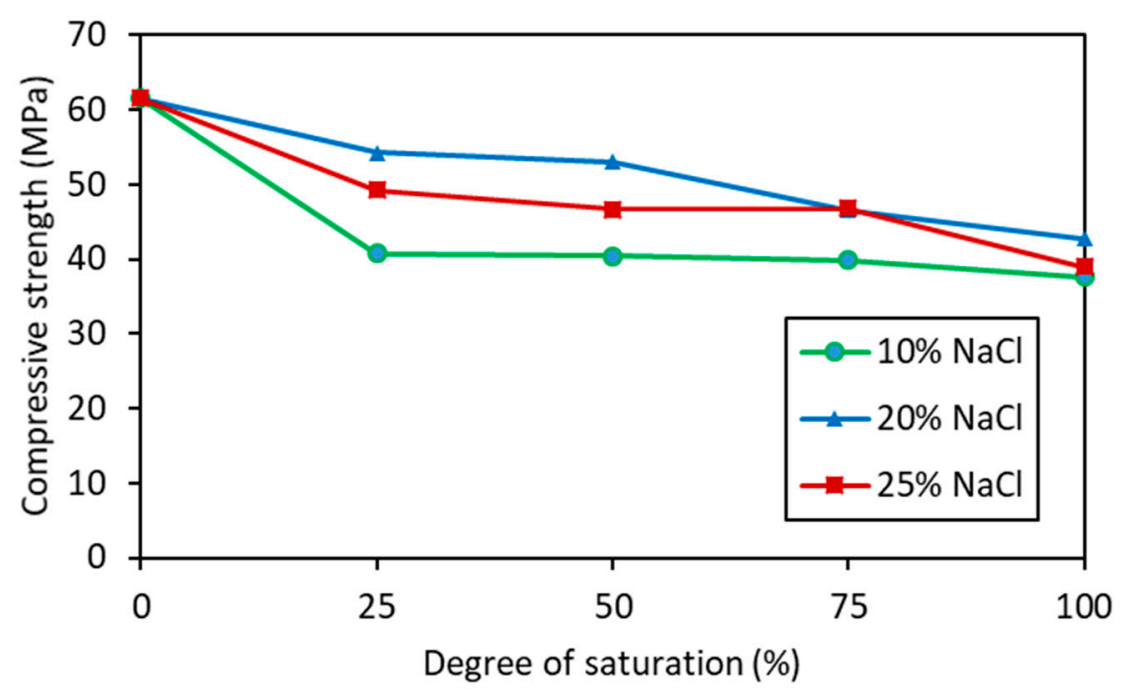

Figure 4. Variation of compressive strength of siltstone in $10 \%, 20 \%$, and $25 \% \mathrm{NaCl}$. 
Table 1. Mechanical properties of dry and brine-saturated siltstone.

\begin{tabular}{|c|c|c|c|c|c|c|c|c|c|c|c|c|c|}
\hline \multirow{2}{*}{$\begin{array}{c}\mathrm{NaCl} \\
\%\end{array}$} & \multirow{2}{*}{ DOS (\%) } & \multicolumn{3}{|c|}{ STS (MPa) } & \multicolumn{3}{|c|}{ UCS (MPa) } & \multicolumn{3}{|c|}{ Poisson's Ratio } & \multicolumn{3}{|c|}{$\mathrm{E}(\mathrm{GPa})$} \\
\hline & & Value & Avg. & SD & Value & Avg. & SD & Value & Avg. & SD & Value & Avg. & SD \\
\hline \multirow{3}{*}{$\begin{array}{c}0 \\
\text { (Dry) }\end{array}$} & 0 DOS-1 & 7.35 & \multirow{3}{*}{7.33} & \multirow{3}{*}{0.03} & 60.78 & \multirow{3}{*}{61.59} & \multirow{3}{*}{0.79} & 0.31 & \multirow{3}{*}{0.30} & \multirow{3}{*}{0.01} & 16.44 & \multirow{3}{*}{16.00} & \multirow{3}{*}{0.32} \\
\hline & 0 DOS-2 & 7.35 & & & 61.32 & & & 0.29 & & & 15.68 & & \\
\hline & 0 DOS-3 & 7.30 & & & 62.66 & & & 0.30 & & & 15.87 & & \\
\hline \multirow{12}{*}{10} & 25 DOS-1 & 6.00 & \multirow{3}{*}{6.20} & \multirow{3}{*}{0.29} & 41.76 & \multirow{3}{*}{40.75} & \multirow{3}{*}{0.80} & 0.33 & \multirow{3}{*}{0.34} & \multirow{3}{*}{0.01} & 12.50 & & \\
\hline & 25 DOS-2 & 6.00 & & & 40.67 & & & 0.35 & & & 12.50 & 12.65 & 0.22 \\
\hline & 25 DOS-3 & 6.61 & & & 39.82 & & & 0.33 & & & 12.96 & & \\
\hline & 50 DOS-1 & 5.60 & & & 38.32 & & & 0.39 & & & 15.80 & & \\
\hline & 50 DOS-2 & 5.73 & 5.60 & 0.10 & 40.33 & 40.38 & 1.70 & 0.36 & 0.37 & 0.01 & 15.91 & 15.51 & 0.49 \\
\hline & 50 DOS-3 & 5.48 & & & 42.48 & & & 0.37 & & & 14.82 & & \\
\hline & 75 DOS-1 & 5.58 & & & 42.07 & & & 0.33 & & & 15.00 & & \\
\hline & 75 DOS-2 & 5.27 & 5.38 & 0.14 & 37.71 & 39.86 & 1.78 & 0.31 & 0.31 & 0.01 & 13.92 & 14.29 & 0.50 \\
\hline & 75 DOS-3 & 5.29 & & & 39.80 & & & 0.30 & & & 13.95 & & \\
\hline & 100 DOS-1 & 5.77 & & & 36.38 & & & 0.28 & & & 13.42 & & \\
\hline & 100 DOS-2 & 5.56 & 5.58 & 0.15 & 38.62 & 37.65 & 0.94 & 0.27 & 0.27 & 0.01 & 12.62 & 12.97 & 0.34 \\
\hline & 100 DOS-3 & 5.40 & & & 37.94 & & & 0.26 & & & 12.86 & & \\
\hline & 25 DOS-1 & 5.77 & & & 55.41 & & & 0.27 & & & 15.34 & & \\
\hline & 25 DOS-2 & 5.93 & 5.70 & 0.22 & 52.98 & 54.31 & 1.00 & 0.27 & 0.26 & 0.01 & 14.89 & 15.41 & 0.45 \\
\hline & 25 DOS-3 & 5.41 & & & 54.53 & & & 0.25 & & & 15.99 & & \\
\hline & 50 DOS-1 & 5.35 & & & 51.32 & & & 0.32 & & & 13.30 & & \\
\hline & 50 DOS-2 & 5.61 & 5.55 & 0.15 & 54.78 & 53.03 & 1.42 & 0.30 & 0.30 & 0.01 & 14.91 & 14.19 & 0.67 \\
\hline 20 & 50 DOS-3 & 5.70 & & & 52.99 & & & 0.28 & & & 14.37 & & \\
\hline & 75 DOS-1 & 5.66 & & & 46.69 & & & 0.22 & & & 13.96 & & \\
\hline & 75 DOS-2 & 5.30 & 5.50 & 0.15 & 48.81 & 46.60 & 1.84 & 0.21 & 0.22 & 0.01 & 12.43 & 13.20 & 0.62 \\
\hline & 75 DOS-3 & 5.54 & & & 44.30 & & & 0.24 & & & 13.21 & & \\
\hline & 100 DOS-1 & 5.68 & & & 42.98 & & & 0.30 & & & 13.30 & & \\
\hline & 100 DOS-2 & 5.30 & 5.51 & 0.16 & 43.68 & 42.80 & 0.80 & 0.33 & 0.31 & 0.01 & 14.60 & 13.75 & 0.60 \\
\hline & 100 DOS-3 & 5.54 & & & 41.75 & & & 0.32 & & & 13.34 & & \\
\hline & 25 DOS-1 & 5.42 & & & 51.35 & & & 0.28 & & & 17.73 & & \\
\hline & 25 DOS-2 & 5.33 & 5.43 & 0.09 & 48.81 & 49.25 & 1.57 & 0.29 & 0.29 & 0.01 & 16.21 & 16.63 & 0.78 \\
\hline & 25 DOS-3 & 5.55 & & & 47.58 & & & 0.30 & & & 15.96 & & \\
\hline & 50 DOS-1 & 5.34 & & & 48.46 & & & 0.29 & & & 12.45 & & \\
\hline & 50 DOS-2 & 5.15 & 5.34 & 0.15 & 44.00 & 46.68 & 1.93 & 0.27 & 0.27 & 0.01 & 11.53 & 12.31 & 0.59 \\
\hline 25 & 50 DOS-3 & 5.53 & & & 47.58 & & & 0.26 & & & 12.96 & & \\
\hline & 75 DOS-1 & 5.02 & & & 43.76 & & & 0.37 & & & 9.99 & & \\
\hline & 75 DOS-2 & 5.02 & 5.17 & 0.21 & 48.33 & 46.76 & 2.12 & 0.38 & 0.37 & 0.01 & 9.53 & 9.55 & 0.35 \\
\hline & 75 DOS-3 & 5.46 & & & 48.19 & & & 0.36 & & & 9.12 & & \\
\hline & 100 DOS-1 & 4.68 & & & 37.99 & & & 0.29 & & & 18.98 & & \\
\hline & 100 DOS-2 & 4.81 & 4.85 & 0.16 & 40.40 & 39.06 & 1.00 & 0.30 & 0.29 & 0.01 & 20.00 & 19.33 & 0.47 \\
\hline & 100 DOS-3 & 5.06 & & & 38.77 & & & 0.28 & & & 19.01 & & \\
\hline
\end{tabular}

Avg-Average value; SD—Standard deviation.

Table 2. Strength classification of intact and jointed rocks (Ramamurthy \& Arora, 1993).

\begin{tabular}{ccc}
\hline Class & Description & UCS (MPa) \\
\hline A & Very high strength & $>250$ \\
B & High strength & $100-250$ \\
C & Moderate strength & $50-100$ \\
D & Medium strength & $25-50$ \\
E & Low strength & $5-25$ \\
F & Very low strength & $<5$ \\
\hline
\end{tabular}




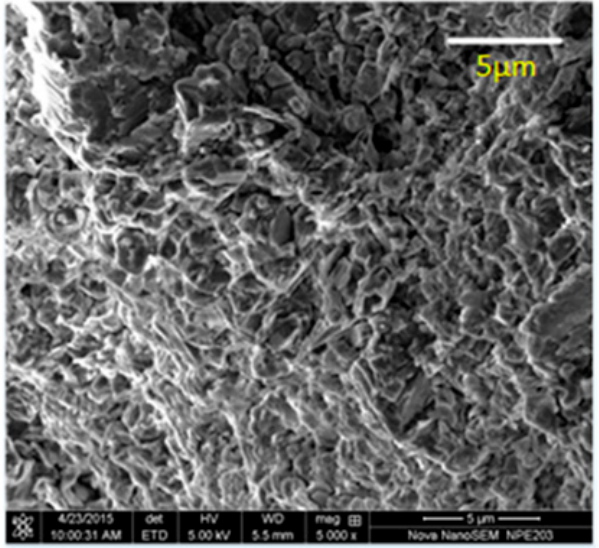

(a)

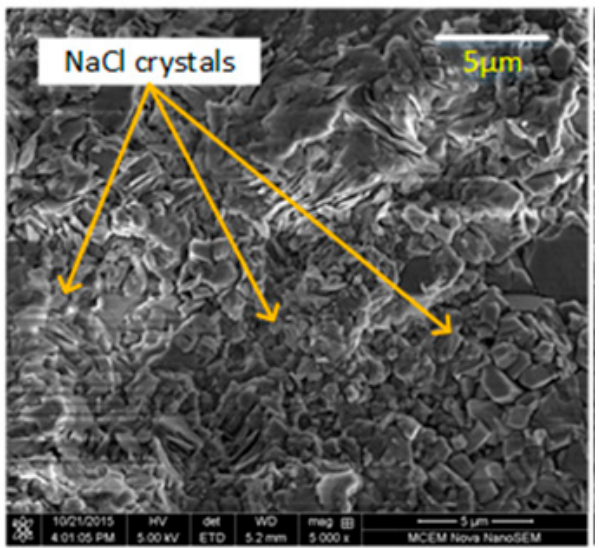

(c)

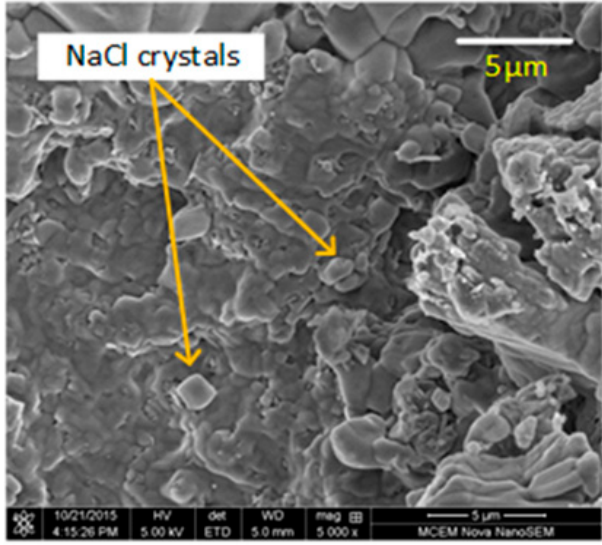

(b)

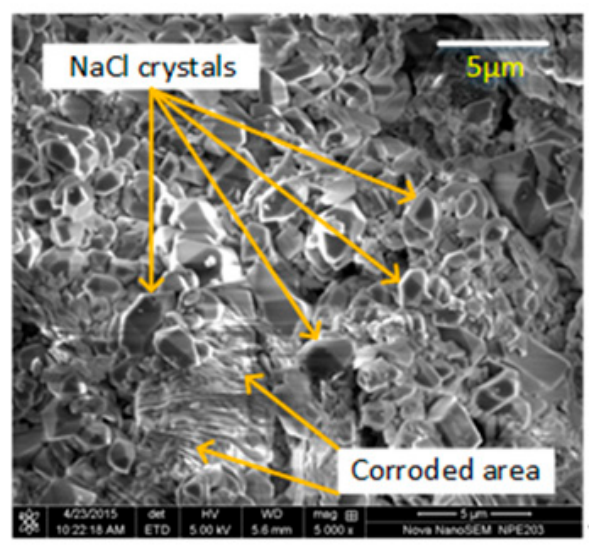

(d)

Figure 5. SEM test results of siltstone specimens (a) dry; (b) $10 \% \mathrm{NaCl}$; (c) $20 \% \mathrm{NaCl}$; (d) $25 \% \mathrm{NaCl}$.

In relation to the influence of $\mathrm{NaCl}$ saturation on strength reduction in various reservoir rocks, the total corresponding UCS reduction observed in this study upon full saturation of siltstone $(100 \%$ DOS) with varying concentrations of brine is around $36 \%(10 \%, 20 \%$, and $25 \% \mathrm{NaCl}$ concentrations cause the siltstone strength to be reduced by around $38.9 \%, 30.5 \%$, and $36.7 \%$, respectively). This is similar to the strength reduction observed for fine grained sandstone (which has similar properties as siltstone) for similar $\mathrm{NaCl}$ saturation conditions by Rathnaweera, Ranjith [29], who also observed around $36.03 \%$ UCS reduction in sandstone with full saturation from $10 \%$ to $30 \% \mathrm{NaCl}$. This is an interesting finding, which shows that the influence of $\mathrm{NaCl}$ saturation is similar for sandstone and siltstone and possible for any reservoir rock. However, this cannot be confirmed without checking the effect for other rock types. Sandstone and siltstone are quite common as shales in unconventional gas reservoirs and therefore, it can be concluded that $\mathrm{NaCl}$ saturation commonly creates a considerable and similar influence on reservoir rocks' UCS strength.

The ARAMIS photogrammetry non-contact and material-independent measuring system was used in this study to investigate the effect of $\mathrm{NaCl}$ concentration and degree of saturation on the deformation characteristics of the siltstone during failure. The ARAMIS photogrammetry images of strain development in the siltstone specimens during failure with their failure patterns are shown in Figure 6. These images have strain contours ranging from blue to red, where blue corresponds to the lowest strain and the red corresponds to the highest strain. As Figure 6 shows, all the images show various colors in the specimens, confirming that the specimens underwent highly varying strain development during failure. The maximum and minimum strain values for $10 \%, 20 \%$, and $25 \%$ brine concentrations are about 0.65 and -0.25 , respectively compared to the dry specimens. However, when both strain and failure patterns are considered, Figure 5 indicates that two main failure types can 
be identified: shear failure and splitting failure. Interestingly, with high $\mathrm{NaCl}$ ionic concentrations $(20 \%$ and $25 \% \mathrm{NaCl}$ concentrations), specimens are more likely to exhibit splitting failure and specimens saturated with low $\mathrm{NaCl}$ ionic concentrations of fluid $(10 \% \mathrm{NaCl})$ are more likely to exhibit shear failure.

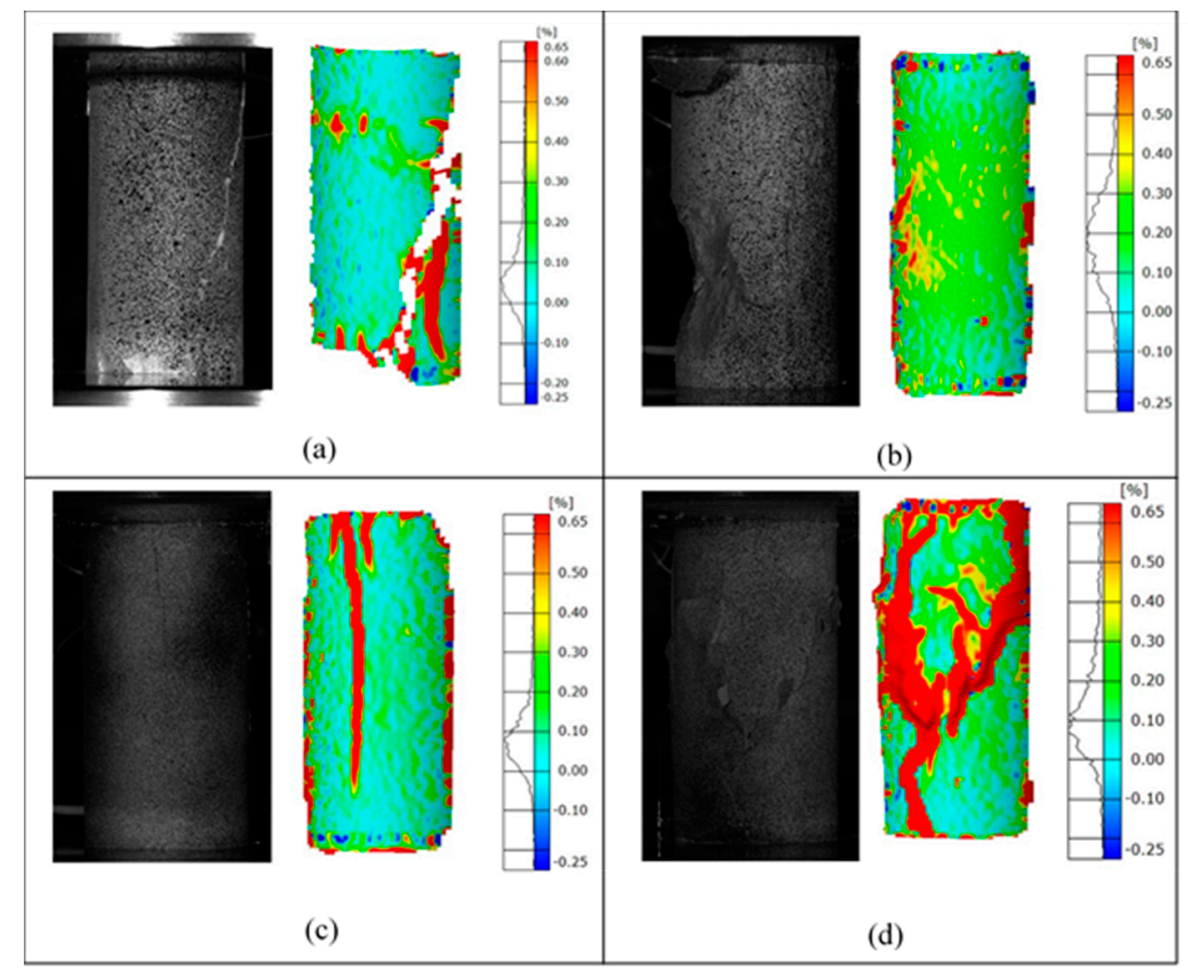

Figure 6. ARAMIS images of specimens of failure (major strain): (a) dry specimen; (b) 10\% brine and $100 \%$ DOS; (c) $20 \%$ brine and 100\% DOS; (d) $25 \%$ brine and $100 \%$ DOS.

\subsection{Effect of Fluid Saturation on Tensile Strength of Siltstone}

In order to identify the effect of fluid saturation on the tensile properties of siltstone, a series of splitting tensile strength (STS) tests were performed on varyingly saturated siltstone specimens (for different concentrations and degrees of saturation of $\mathrm{NaCl}$ ) and the results are shown in Figure 7 . Similar to the compressive strength tests, triplicate specimens were tested for each saturation condition (see Table 1) and the average strength value was used as the tensile strength under each saturation condition. The STSs of the varyingly saturated specimens are between $4.85 \mathrm{MPa}$ and $7.33 \mathrm{MPa}$. According to Figure 6, dry siltstone has the maximum tensile strength similar to the compressive strength and it continuously reduces with increasing degree of saturation of $\mathrm{NaCl}$ ionic solution at any concentration, which is related to the water softening effect and quartz mineral dissolution. However, the initial strength reduction that occurs due to up to $25 \% \mathrm{DOS}$ of $\mathrm{NaCl}$ ionic solution appears to be much greater than the tensile strength reduction which occurs with further increase of DOS, up to $100 \%$. For example, up to $64 \%, 89 \%$, and $76 \%$ total strength reductions in $10 \%, 20 \%$, and $25 \% \mathrm{NaCl}$ saturated specimens occur at $25 \%$ DOS. The total porosity of the tested siltstone should be greater than $20 \%$, because according to the mercury intrusion porosity tests, the inter-granular porosity (effective porosity) of the tested siltstone is around $20 \%$. However, this particular test can only provide the porosity available in material for mercury intrusion or in other words inter-granular pores. Since some inter-granular pores may be in closed loops and they may not contribute to the intrusion and the total porosity may therefore be slightly greater than $20 \%$. However, it should be noted that not the effective porosity, the total porosity is governing fact for rock mechanical properties. The variation of the incremental intrusion volume with the pore diameter is given in Figure 8, according to which, pore size diameter is mainly concentrated around $1 \mu \mathrm{m}$ and $100 \mu \mathrm{m}$, and $\mathrm{NaCl}$ ions (molecular size $<1 \mu \mathrm{m}$ ) 
can easily enter the inter-granular pores and break the bond between the rock grains. This may cause a significant strength reduction at $25 \%$ DOS.

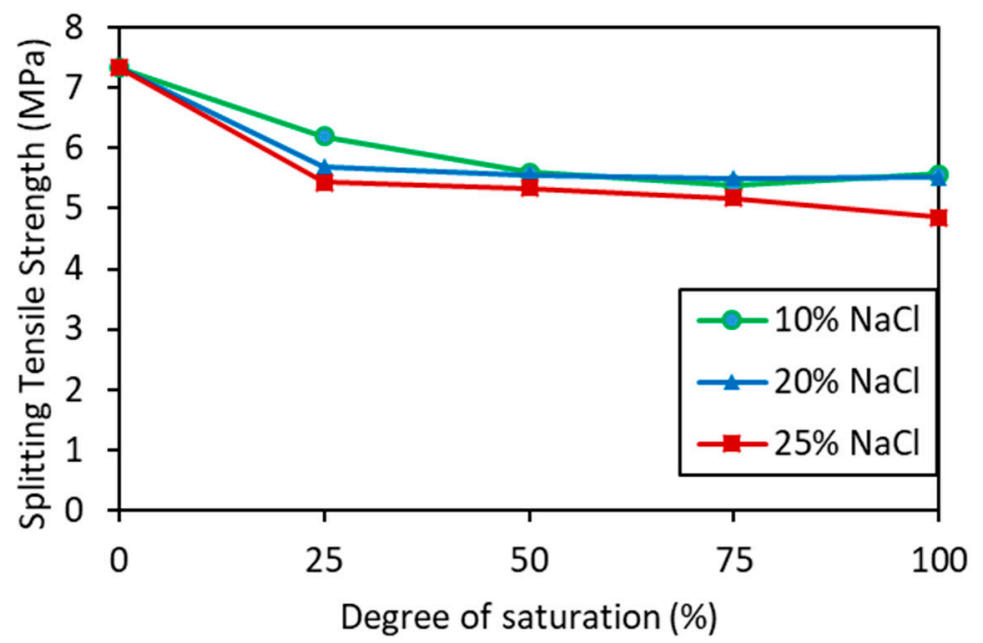

Figure 7. Variation of splitting tensile strength of siltstone in $10 \%, 20 \%$, and $25 \% \mathrm{NaCl}$.

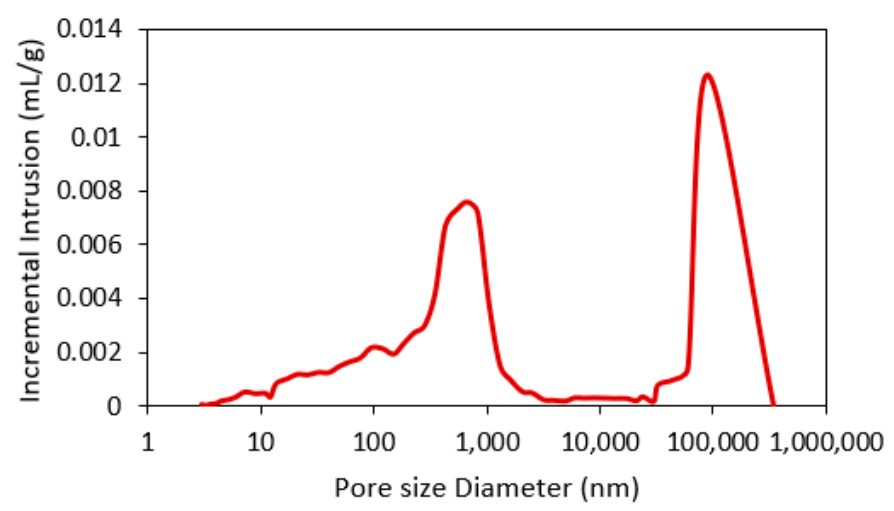

Figure 8. Pore size distribution of tested siltstone.

Importantly, according to Figure 7, the tensile strength of the siltstone at any DOS continuously decreases with increasing $\mathrm{NaCl}$ concentration, which is different from the compressive strength reduction observed upon $\mathrm{NaCl}$ saturation. The reduction of tensile strength with increasing ionic strength of the $\mathrm{NaCl}$ ionic solution from $10 \%$ to $25 \%$ is possibly related to the interaction of $\mathrm{NaCl}$ ions with the siltstone rock matrix (a corrosive influence described in compressive strength reduction), and such interaction is obviously greater at greater ionic concentrations. According to existing studies [42,43], rock minerals such as quartz and kaolinite are highly reactive with $\mathrm{NaCl}$, and the siltstone studied here is abundant with these rock minerals. We can therefore expect a highly reactive environment inside the rock with $\mathrm{NaCl}$ saturation. The possible reactions that occur among quartz and kaolinite with $\mathrm{NaCl}$ are shown in Equations (2) and (3). According to these equations, these reactions commonly release $\mathrm{HCl}$ into the reservoir pore fluid, making the pore fluid more acidic. Such an acidic environment has a strong influence on breaking the grain-to-grain bonds in the rock, reducing its tensile strength and its compressive strength. However, one might be curious to know why the $\mathrm{NaCl}$ crystallization effect does not affect the tensile strength of siltstone. This is because of the difference between the load application in tensile and compressive loading. In compression, the load is applied on the bulk material, and under such conditions the reduced pore space filled with $\mathrm{NaCl}$ crystals offers more barriers to failing the specimen under compression as the $\mathrm{NaCl}$ crystals also bear some compressive loading. However, in tensile load application, the rock matrix is fractured by the load, and in such situations the existence of weak $\mathrm{NaCl}$ crystals in rock pore space does not help, as the whole rock is 
fracturing through its strongest section or rock matrix. Overall, only the grain corrosion effect created by the ions of the saturation fluid affects the tensile strength of siltstone. This is quite important for the hydro-fracturing process, as in this process fracture propagation mainly occurs through tensile failure. Therefore, tensile strength is the governing factor for the fracking process. According to the findings of this study, the hydro-fracturing process is only influenced by this grain corrosion effect created by the ions of the saturation fluid. Therefore, a higher ionic concentration creates a more favorable environment for the fracturing process.

$$
\begin{gathered}
\mathrm{SiO}_{2}(\text { quartz })+\mathrm{NaCl}+\mathrm{H}_{2} \mathrm{O}=\mathrm{H}_{3} \mathrm{NaSiO}_{4}+\mathrm{HCl} \\
\mathrm{Al}_{2} \mathrm{Si}_{2} \mathrm{O}_{5}(\mathrm{OH})_{4}(\text { kaolinite })+2 \mathrm{NaCl}=2 \mathrm{NaAlSiO}_{4}+2 \mathrm{HCl}+\mathrm{H}_{2} \mathrm{O}
\end{gathered}
$$

The failure patterns of the varyingly saturated siltstone specimens under indirect tensile loading were obtained by ARAMIS photogrammetry and the results are shown in Figure 9. Interestingly, all the siltstone specimens under all saturation conditions appear to have undergone splitting failure with greater strain concentrations at the contact points, in accordance with the ASTM standard. According to the strain contours, maximum and minimum strain values at failure are around 0.20 and -0.075 , respectively, which appear to only slightly vary with $\mathrm{NaCl}$ concentration or DOS levels. Moreover, in dry specimens and $10 \% \mathrm{NaCl}$-saturated specimens, failure occurred suddenly and the entire specimen split into two parts (the width of the failure fracture is large) during the load application. In contrast, in $20 \%$ and $25 \% \mathrm{NaCl}$-saturated specimens, failure occurred with much slower fracture propagation.

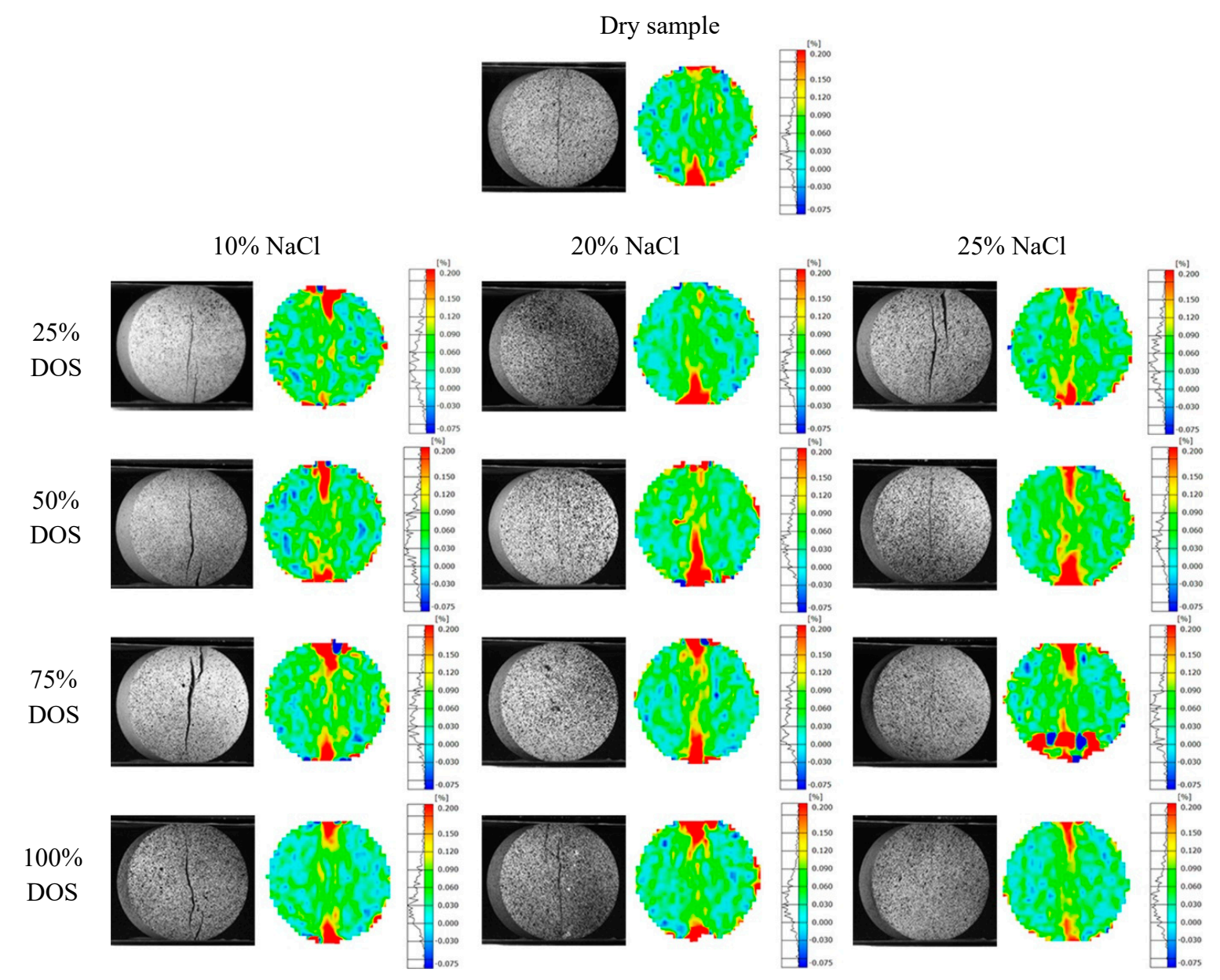

Figure 9. ARAMIS strain distribution ( $-0.075 \%-0.2 \%$ ) and failure pattern in STS specimens for $10 \%$, $20 \%$ and $25 \% \mathrm{NaCl}$ concentrations for $25 \%, 50 \%, 75 \%$, and $100 \%$ degree of saturation (DOS). 


\subsection{Effect of Fluid Saturation on Brittle Characteristics of Siltstone}

The stress-strain behavior of varyingly saturated siltstone specimens obtained from the UCS tests was then used to identify the influence of various saturations on their brittle characteristics. This is because, as explained in the introduction, brittle rocks more likely to have more favorable responses to the fracturing process than ductile rocks. In order to identify the saturation-induced brittle characteristic alterations in siltstone, the elastic modulus (E) and Poisson's ratio ( $v$ ) of each specimen were calculated using the stress-strain curves given in Figure 10. The average values for three replicates are shown in Table 1. As the table shows, the standard variation among the $\mathrm{E}$ and $v$ values among the tested triplicated specimens are at about the $5 \%$ range and therefore, the average values give a reasonable representation of the siltstone tested. Thee specimens were collected from same block and were therefore expected to have the same micro-structure and mineral composition and therefore the same mechanical properties, as shown in Table 1.

(a)

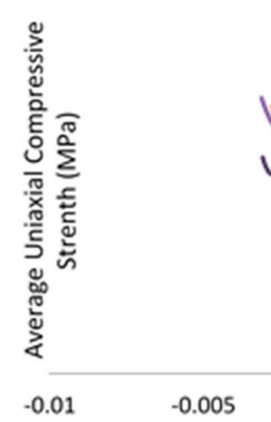

Lateral Strain

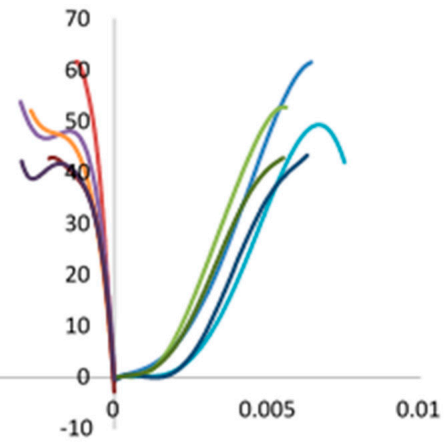

Axial $\overline{\text { Strain }}$ DOS=100- Lateral strain

(b)

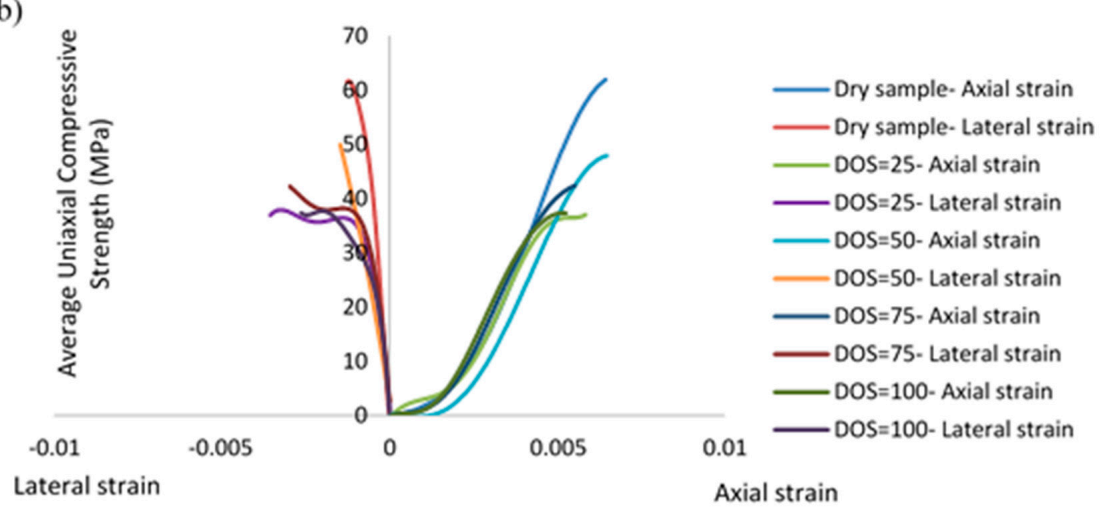

(c)

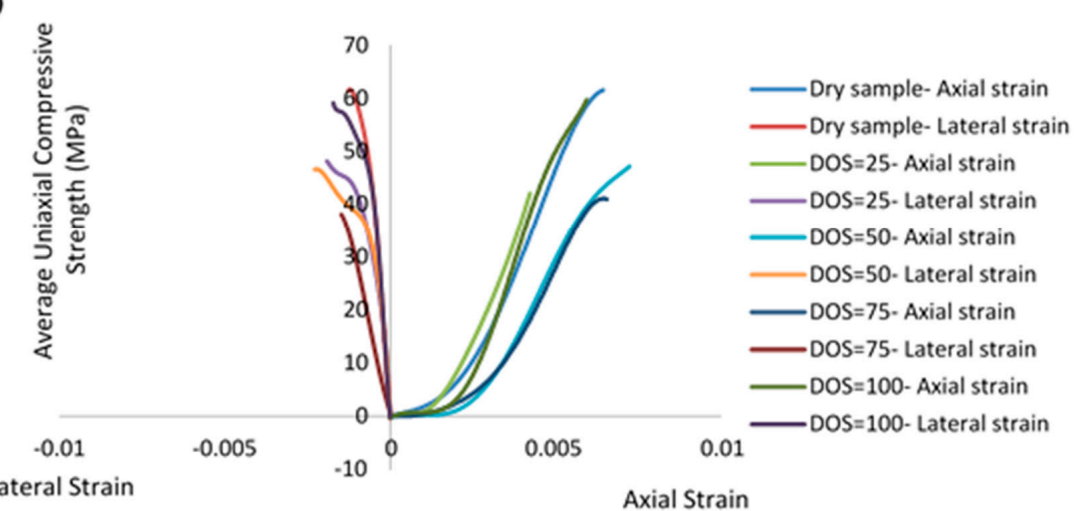

Figure 10. Stress-strain curves for (a) $10 \% \mathrm{NaCl}$ concentration; (b) $20 \% \mathrm{NaCl}$ concentration; (c) $25 \%$ $\mathrm{NaCl}$ concentration. 
According to Figure 11a, the elastic moduli of dry and saturated specimens vary between 19.33 and $9.55 \mathrm{GPa}$, the dry specimens commonly have the highest elastic modulus (E) (around $16 \mathrm{GPa}$ ), and saturation generally causes the reduction of the $\mathrm{E}$ values of the siltstone. If the effect of $\mathrm{NaCl}$ DOS on the rock specimen E values is considered, elastic modulus seems to generally decrease with increasing degree of saturation. This is consistent with the $\mathrm{E}$ reduction behavior with brine saturation observed by Nasvi, Ranjith [30] for sandstone and geo-polymer. The reduction of elastic modulus represents the enhancement of ductile properties in the siltstone with $\mathrm{NaCl}$ saturation, regardless of saturation condition. This proves that increasing $\mathrm{NaCl}$ ionic concentration causes the siltstone's brittle properties to be reduced. The interaction of strong $\mathrm{NaCl}$ ions with the siltstone rock matrix possibly changes its polymer structure. However, this is not favorable for the hydro-fracturing process, as ductile rocks need more energy for fracturing compared to brittle rocks. According to Dyke and Dobereiner [44], the polymer structure of the siltstone rock matrix can be changed by the exchange of strong $\mathrm{Si}-\mathrm{O}-\mathrm{Si}-$ bonds with weaker hydrogen bonds which eventually breaks the strong inter-granular atomic bonds, resulting in enhanced ductile properties. If the hydro-fracturing process is considered, additional costs and a greater injection pressure are required to create fractures in the reservoir rock with enhanced ductile properties, which is certainly not a favorable condition.

Interestingly, as can be clearly seen in Figure $11 \mathrm{a}$, when the $\mathrm{NaCl}$ concentration is $25 \%$, there is a quite high E value (19.33 GPa) in the tested siltstone for the $100 \%$ saturated condition, which is even higher than the $\mathrm{E}$ value for the dry condition (16 GPa). This high $\mathrm{E}$ value for this particular saturation condition can be observed in all the triplicated specimens (Table 1). Therefore, this result is reliable although unexpected. It is possible that, at high salinity concentrations, the occurrence of $\mathrm{NaCl}$ crystals in the pore structure is much harder than at low saturation conditions. Therefore, the generally expected brittle characteristic affects the failure behavior of the siltstone. This is confirmed by the fact that this is seen only at $100 \%$ degree of saturation, at which all the pores are fully filled with $\mathrm{NaCl}$ and there is therefore a higher probability for applied load to be transferred through the $\mathrm{NaCl}$ crystals.

In relation to the effect of $\mathrm{NaCl}$ ionic solution saturation on siltstone's Poisson's ratio, according to Figure 11b, the Poisson's ratios of varyingly saturated siltstone specimens (including dry) are in the 0.22 to 0.37 range. However, a closer look on Figure $11 \mathrm{~b}$ shows that there is no such direct influence of $\mathrm{NaCl}$ saturation on the tested siltstone, and the variation of the Poisson's ratio with $\mathrm{NaCl}$ concentration and DOS appears to be random. However, more tests need to be performed before coming to a final conclusion.

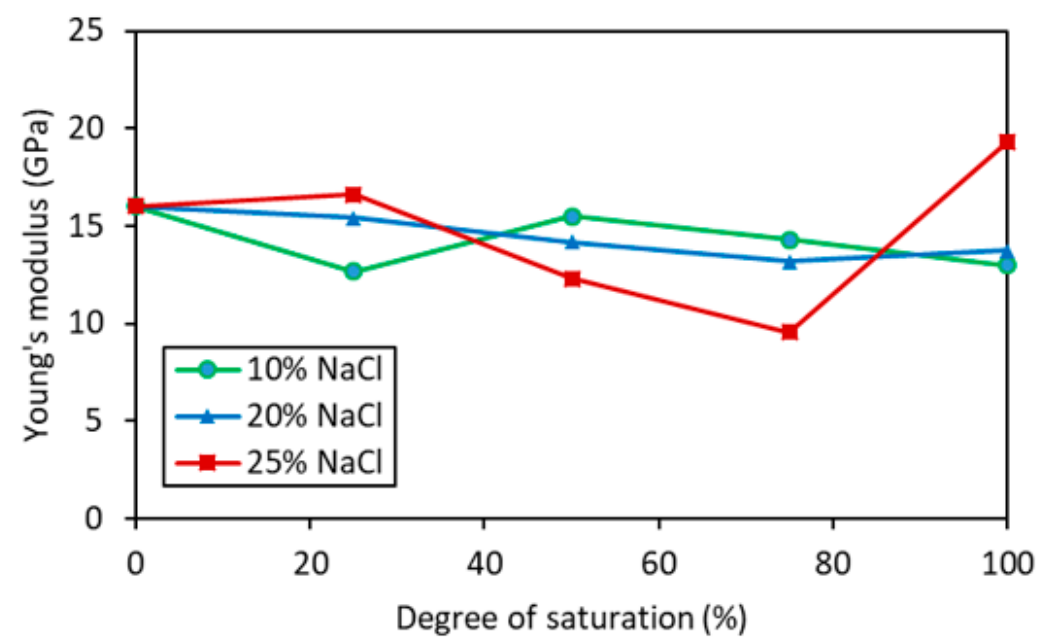

(a)

Figure 11. Cont. 


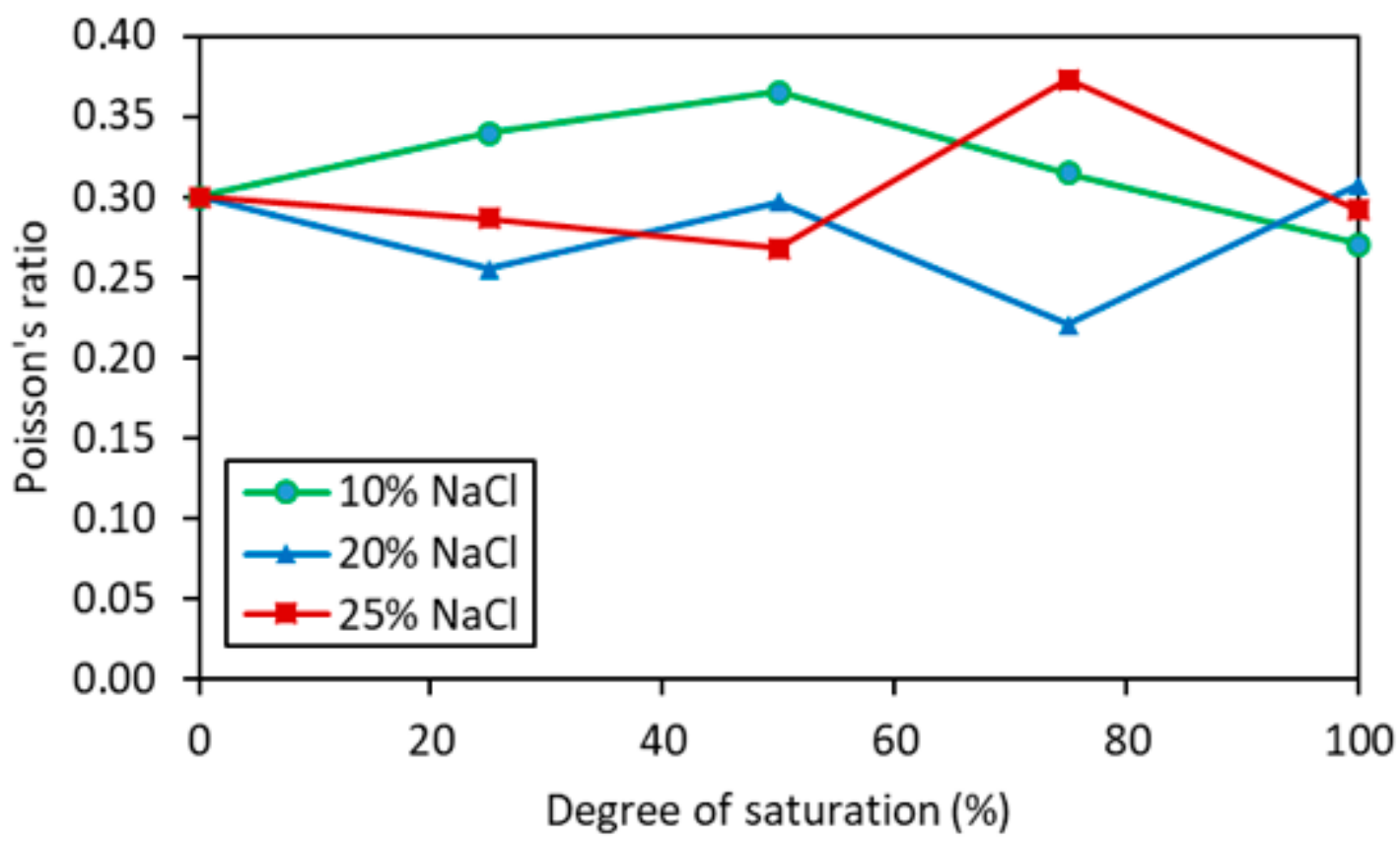

(b)

Figure 11. Variation of (a) Yong's modulus and (b) Poisson's ratio of siltstone in $10 \%, 20 \%$, and $25 \% \mathrm{NaCl}$.

\subsection{Effect of Fluid Saturation on Fracture Propagation in Siltstone}

The fracture propagation in the reservoir rock is highly important in the hydro-fracturing process, and may be affected by the properties of the pore fluid and the saturation conditions. Therefore, this was considered in the next stage of the study, based on comprehensive acoustic emission (AE) analysis. AE capture and analysis is one of the most effective methods to understand crack propagation behavior in rocks, having the ability to effectively exhibit the major fracture propagation steps under load application: crack initiation, crack propagation and final failure [45-49]. Among the initial step belongs to initiation of AE release upon load application, where in the beginning of load application there is no any crack in the rock or rock at crack closure state and continuous load application causes to initiate cracks at one stage and this is called crack initiation. Further load application on the rock beyond this point causes the created cracks to propagate through the rock with continuously increasing $\mathrm{AE}$ energy release. This is called crack propagation. In this region a gradual AE release can be seen and this is called stable crack propagation. This is followed by more rapid or exponential energy release, called unstable crack propagation. Further increasing of load beyond unstable crack propagation causes the rock to fail $[35,49,50]$.

In the present study, $\mathrm{AE}$ technology was utilized to identify the effect of $\mathrm{NaCl}$ saturation on crack formation behavior in siltstone specimens. The results of measured cumulative AE energy with axial stress for varyingly saturated specimens, including dry specimens, are shown in Figure 12. The failure occurring stress threshold values for each DOS under the considered three brine concentration levels are shown in Table 3. According to Figure 12 and Table 3, dry specimen is at crack closure stress condition up to 5.3 MPa axial stress, where is crack closer period will be reduced up 4.3 MPa and 3.4 MPa at the presence of $10 \%$ and $20 \%$ brine in the pore fluid and is increased up to around $6.7 \mathrm{MPa}$ at the presence of $25 \%$ concentration brine in the pore fluid at fully saturated $(100 \%$ DOS) condition. Upon crack initiation, the released AE energy increases almost linearly up to around $23.8 \mathrm{MPa}, 17.6 \mathrm{MPa}, 17.2 \mathrm{MPa}$, and $20.5 \mathrm{MPa}$ in dry, $10 \%, 20 \%$, and $25 \%$ brine-saturated specimens, respectively under fully saturated conditions (100\% DOS). However, this energy release trend in $25 \%$ brine-saturated specimens is quite different from the other specimens (dry, 10\%, 20\% brine saturated specimens), where when 
the specimen is saturated with high concentrations of $\mathrm{NaCl}$ ( $25 \%$ here), two fracture propagation periods can be seen. This is probably due to the previously-mentioned hard $\mathrm{NaCl}$ crystallization effect, where the fracture propagation occurred in these pores filled with this strong $\mathrm{NaCl}$ crystals may be exhibited through this secondary fracture propagation and specimen would fail only after completion of the both fracture propagation. This shows the importance of the $\mathrm{NaCl}$ ionic concentration for fracture propagation behavior in reservoir rock.

(a)

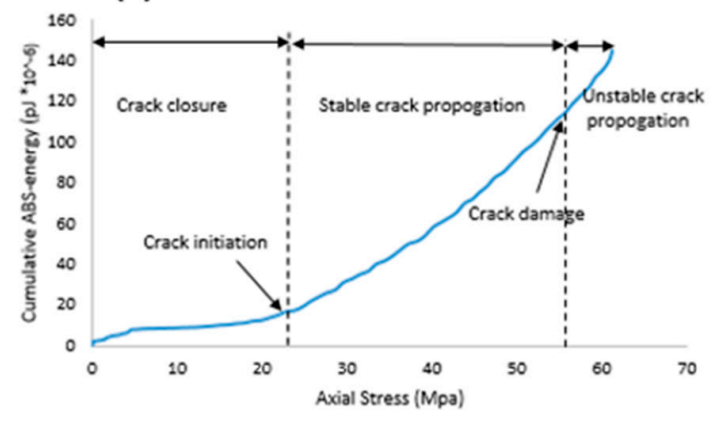

(c)

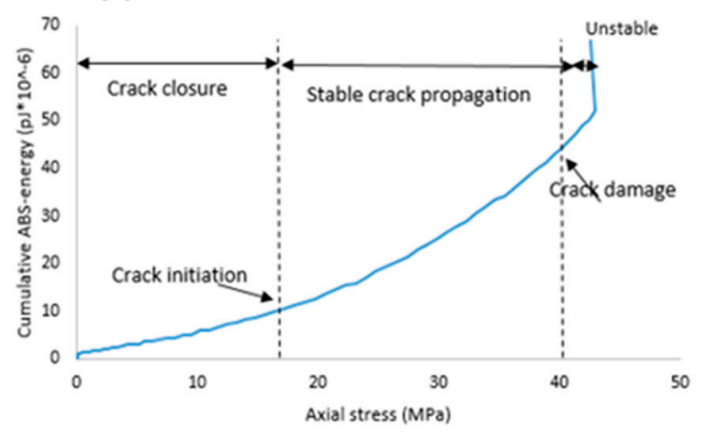

(b)

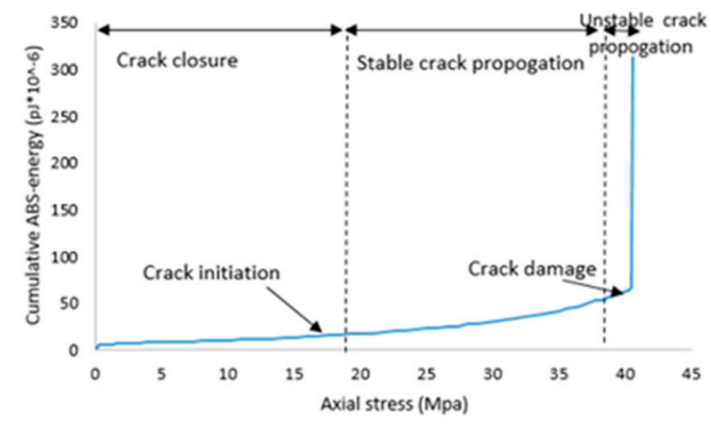

(d)

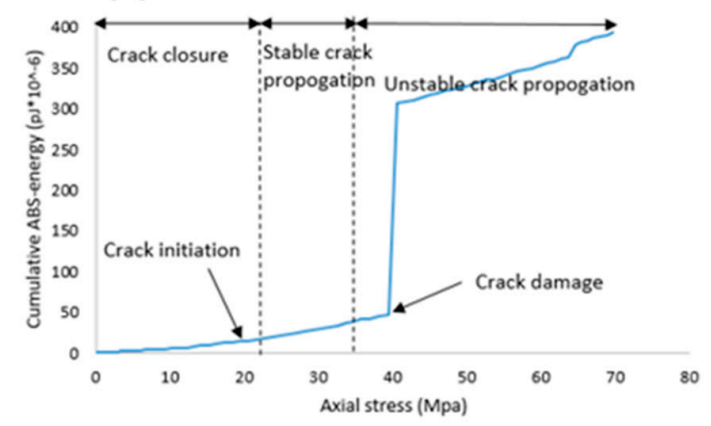

Figure 12. Cumulative absolute energy with axial stress for (a) dry specimen; (b) $10 \% \mathrm{NaCl}$; (c) $20 \%$ $\mathrm{NaCl}$-saturated specimen; (d) 25\% NaCl-saturated specimen.

According to Figure 12, the $\mathrm{NaCl}$ concentration of the brine solution of the rock specimens has a clear effect on the energy released from the acoustic system. Increasing the $\mathrm{NaCl}$ concentration causes a greater degree of AE energy release, which is to be expected, as the electron conductivity of brine increases with increasing numbers of $\mathrm{NaCl}$ ions or $\mathrm{NaCl}$ concentration, as this affects the transferability of the acoustic energy released from the rock to the sensors through the pore fluid [29]. However, this is also affected by the $\mathrm{NaCl}$ crystallization effect, where the greater the $\mathrm{NaCl}$ concentration, the greater the ability to create $\mathrm{NaCl}$ crystals in the rock pore space. The application of load on the rock not only breaks the rock matrix, it also causes the $\mathrm{NaCl}$ crystals to break, causing a higher number of $\mathrm{AE}$ counts.

The influence of brine saturation on fracture formation behavior in reservoir rock is clear and therefore needs to be considered in the hydro-fracturing process.

Table 3. Stress threshold value for dry and $\mathrm{NaCl}$-saturated specimens.

\begin{tabular}{ccccccccccccc}
\hline & \multicolumn{4}{c}{$\mathbf{1 0} \% \mathbf{~ N a C l}$} & \multicolumn{4}{c}{$\mathbf{2 0} \% \mathbf{~ N a C l}$} & \multicolumn{4}{c}{$\mathbf{2 5 \%} \mathbf{~ N a C l}$} \\
\hline DOS $(\%)$ & $\sigma_{\mathrm{cc}}$ & $\sigma_{\mathrm{ci}}$ & $\sigma_{\mathrm{cd}}$ & $\sigma_{\mathrm{ucs}}$ & $\sigma_{\mathrm{cc}}$ & $\sigma_{\mathrm{ci}}$ & $\sigma_{\mathrm{cd}}$ & $\sigma_{\mathrm{ucs}}$ & $\sigma_{\mathrm{cc}}$ & $\sigma_{\mathrm{ci}}$ & $\sigma_{\mathrm{cd}}$ & $\sigma_{\mathrm{ucs}}$ \\
\hline 0 & 5.3 & 23.8 & 55.8 & 61.3 & 5.3 & 23.8 & 55.8 & 61.3 & 5.3 & 23.8 & 55.8 & 61.3 \\
25 & 1.3 & 14 & 40 & 41.5 & 2.4 & 20 & 61 & 65.3 & 9.2 & 30.7 & 57.9 & 59.4 \\
50 & 2.5 & 20 & 60 & 61.6 & 2.5 & 18 & 70 & 74 & 3.4 & 12.9 & 47.8 & 48.4 \\
75 & 7 & 18 & 46.9 & 48.6 & 12.6 & 18.6 & 43.7 & 46.6 & 5.5 & 13.1 & 41.5 & 43.7 \\
100 & 4.3 & 17.6 & 39 & 40.6 & 3.4 & 17.2 & 41.4 & 42.9 & 6.7 & 20.5 & 40 & 68.9 \\
\hline
\end{tabular}

$\sigma_{\mathrm{cc}}-$ Stress at crack closure; $\sigma_{\mathrm{ci}}-$ Stress at crack initiation; $\sigma_{\mathrm{cd}}-$ Stress at crack damage; $\sigma_{\mathrm{ucs}}-$ Stress at crack final failure. 


\subsection{Correlation of Reservoir Rock strength with $\mathrm{NaCl}$ Ionic Concentration and its DOS}

According to the all the research findings summarized above, the significant influence of $\mathrm{NaCl}$ ionic concentration and saturation level on reservoir rock compressive and tensile strengths is clear. An effort was therefore made to develop a relationship to exhibit the influence of these $\mathrm{NaCl}$ ionic solution properties on both the compressive and tensile strength of siltstone, by performing non-linear regression analysis using measured data and MATLAB software. The obtained relationships are shown in Equations (4) and (5). The first shows how the compressive strength of siltstone varies with $\mathrm{NaCl}$ ionic concentration and saturation and the other shows how the tensile strength of the same rock varies with these parameters, and both are in the $99 \%$ confidence band. However, it should be noted that the developed equations can only be used for Eidsvold siltstones with the brine conditions considered here.

$$
\begin{gathered}
\sigma_{c}=-80.2145 D+134.2635 D^{2}-76.6561 D^{3}+346.2722 C-908.417 C^{2}+4.5637 C D+32.0057 \\
\sigma_{t}=-8.4069 D+12.9294 D^{2}-6.2115 D^{3}+9.6456 C-32.5277 C^{2}-1.7638 C D+6.7607
\end{gathered}
$$

where $\sigma_{\mathrm{C}}$ is the average UCS, $\sigma_{\mathrm{t}}$ is the average STS, D is the degree of saturation and $\mathrm{C}$ is the $\mathrm{NaCl}$ concentration in percentage by weight. It is important to note that in Equations (4) and (5), the $C$ and $D$ values are in decimals.

To date, no data are available on the effect of brine concentration and degree of saturation on the mechanical properties of siltstone reservoirs. The findings of this study are therefore vital for the hydro-fracturing process in low permeable reservoir rocks and will enable identification of the effects of $\mathrm{NaCl}$ concentration and degree of saturation on the strength properties and therefore the hydro-fracturing process in low permeable reservoir rocks such as shales. However, the mechanical properties of such reservoir rocks also vary with the injection fluid properties. Therefore, further studies are suggested to obtain a comprehensive understanding of the subject.

\section{Conclusions}

The presence of brine in reservoir rock pores is believed to have an important influence on the hydro-fracturing process in unconventional gas extraction. This was considered in this study by conducting a wide range of laboratory tests (UCS and STS experiments) for varyingly saturated siltstone specimens and observing their fracture propagation behavior (AE and ARMIS technologies). According to current research findings:

$>$ Any type of $\mathrm{NaCl}$ ionic solution causes the strength to be reduced, mainly through weakening the bonding between the clay mineral and rock and breaking the solid-solid bonds and creating new weaker solid-liquid bonds. For example, dry specimens exhibited the highest UCS value in testing (61.6 MPa) and full saturation with $10 \%, 20 \%$, and $25 \% \mathrm{NaCl}$ caused the strength to be reduced by around $38.9 \%, 30.5 \%$, and $36.7 \%$, respectively.

$>$ Increasing the $\mathrm{NaCl}$ concentration in saturation fluid generally enhances the compressive strength of the rock through the $\mathrm{NaCl}$ crystallization effect in the pore structure, an excessive amount of $\mathrm{NaCl}$ molecules may cause the rock strength to be reduced through the corrosive influence which occurs at high ionic concentrations. For example, according to the test results, there is a strength increment in brine-saturated specimens up to $20 \% \mathrm{NaCl}$ concentration of the saturation fluid and further increasing the $\mathrm{NaCl}$ ionic concentration to $25 \%$ causes strength reduction.

$>$ Similar to the compressive strength, the tensile strength of siltstone also decreases with $\mathrm{NaCl}$ ionic solution saturation, due to the same bond breaking and weakening effects.

$>$ However, the rate of strength reduction becomes much smaller after a particular degree of saturation, probably after filling the inter-granular pores. For example, in the test results, there is a high strength reduction in siltstone up to $25 \% \mathrm{DOS}$ and further increasing the $\mathrm{NaCl}$ ionic solution saturation level up to $100 \%$ DOS causes the reduction rate to be significantly reduced. 
$>$ Further, increasing the $\mathrm{NaCl}$ ionic concentration at any DOS causes siltstone tensile strength to be reduced, probably due to the interaction of $\mathrm{NaCl}$ ions with the siltstone rock matrix or the corrosive influence that is obviously greater at greater ionic concentrations. However, this trend is different to the compressive strength behavior, because the significant influence of $\mathrm{NaCl}$ crystals on compressive strength does not affect the tensile strength much due to the different load application. This is quite important for the hydro-fracturing process, as in this process fracture propagation mainly occurs through tensile failure and tensile strength is therefore the governing factor for the fracking process.

> Regarding the effect of $\mathrm{NaCl}$ ionic solution saturation on the brittle characteristics of siltstone, saturation of siltstone with any $\mathrm{NaCl}$ ionic concentration generally causes its ductile properties to be enhanced, and the influence is greater at greater DOS, due to the polymer structure rearrangement which occurs in siltstone with fluid saturation. For example, according to the results, the elastic moduli of dry and saturated specimens vary between 19.33 and $9.55 \mathrm{GPa}$, and the dry specimens commonly have the highest elastic modulus and any saturation generally causes the $\mathrm{E}$ value to decrease. This is however not favorable for the hydro-fracturing process, as ductile rocks need more energy for fracturing, compared to brittle rocks.

$>$ However, having very highly concentrated $\mathrm{NaCl}$ ionic solution in siltstone causes its brittle properties to be enhanced, perhaps under high salinity concentrations, $\mathrm{NaCl}$ crystals occur in pore structure is much harder than low salinity concentrations and therefore the generally expecting its brittle characteristic affects the overall failure behavior of the siltstone. For example, according to the results, when the $\mathrm{NaCl}$ concentration is $25 \%$, there is a quite high $\mathrm{E}$ value $(19.33 \mathrm{GPa})$ in the tested siltstone for the $100 \%$ saturation condition, which is even higher than the $\mathrm{E}$ value for the dry condition (16 GPa).

To date, little information is available on the effect of brine concentration and degree of saturation on the mechanical properties of siltstone reservoirs. The findings of this study are therefore vital for the hydro-fracturing process in low permeable reservoir rocks. This study will enable the identification of the effects of $\mathrm{NaCl}$ concentration and degree of saturation on the strength properties, and therefore improve the understanding on hydro-fracturing process in low permeable reservoir rocks such as shales.

Author Contributions: A.W., R.P.G. and Q.L. conceived and designed the experiments; H.W. and A.W. performed the experiments; S.P. and T.R. analyzed the data; A.W. wrote the paper.

Funding: This research was funded by the China Postdoctoral Science Foundation grant number 2018M630913.

Acknowledgments: The authors would like to thank all the technical staffs of the Geo-lab at Monash University for their help with the experimental work and the financial support from the China Postdoctoral Science Foundation (Grant No.: 2018M630913).

Conflicts of Interest: The authors declare that they have no conflict of interest.

Ethical approval: All procedures performed in studies involving human participants were in accordance with the ethical standards of the institutional and/or national research committee and with the 1964 Helsinki declaration and its later amendments or comparable ethical standards. This article does not contain any studies with animals performed by any of the authors.

Informed Consent: Informed consent was obtained from all individual participants included in the study.

\section{References}

1. Perera, M.; Ranjith, P.; Choi, S.-K.; Bouazza, A. A parametric study of coal mass and cap rock behaviour and carbon dioxide flow during and after carbon dioxide injection. Fuel 2013, 106, 129-138. [CrossRef]

2. Perera, M.; Ranjith, P.; Ranathunga, A.; Koay, A.; Zhao, J.; Choi, S. Optimization of enhanced coal-bed methane recovery using numerical simulation. J. Geophys. Eng. 2015, 12, 90. [CrossRef]

3. Ellabban, O.; Abu-Rub, H.; Blaabjerg, F. Renewable energy resources: Current status, future prospects and their enabling technology. Renew. Sustain. Energy Rev. 2014, 39, 748-764. [CrossRef] 
4. Guo, B.; Ghalambor, A. Natural Gas Engineering Handbook; Elsevier: Amsterdam, The Netherlands, 2014.

5. Wasantha, P.; Ranjith, P.; Zhang, Q.; Xu, T. Do joint geometrical properties influence the fracturing behaviour of jointed rock? An investigation through joint orientation. Geomech. Geophys. Geo-Energy Geo-Resour. 2015, 1, 3-14. [CrossRef]

6. Yang, Y.; Ju, Y.; Sun, Y.; Zhang, D. Numerical study of the stress field during crack growth in porous rocks. Geomech. Geophys. Geo-Energy Geo-Resour. 2015, 1, 91-101. [CrossRef]

7. Pacala, S.; Socolow, R. Stabilization wedges: Solving the climate problem for the next 50 years with current technologies. Science 2004, 305, 968-972. [CrossRef]

8. Kargbo, D.M.; Wilhelm, R.G.; Campbell, D.J. Natural gas plays in the marcellus shale: Challenges and potential opportunities. Environ. Sci. Technol. 2010, 44, 5679-5684. [CrossRef]

9. Ahmed, N.A.; Cameron, M. The challenges and possible solutions of horizontal axis wind turbines as a clean energy solution for the future. Renew. Sustain. Energy Rev. 2014, 38, 439-460. [CrossRef]

10. Zhang, J.; Yu, M.; Al-Bazali, T.; Ong, S.; Chenevert, M.E.; Sharma, M.M.; Clark, D.E. Maintaining the stability of deviated and horizontal wells: Effects of mechanical, chemical and thermal phenomena on well designs. In Proceedings of the International Oil \& Gas Conference and Exhibition in China, Beijing, China, 5-7 December 2006; Society of Petroleum Engineers: Richardson, TX, USA, 2006.

11. Zhang, G.-Q.; Fan, T. A high-stress tri-axial cell with pore pressure for measuring rock properties and simulating hydraulic fracturing. Measurement 2014, 49, 236-245. [CrossRef]

12. Wanniarachchi, W.; Ranjith, P.; Perera, M.; Lashin, A.; Al Arifi, N.; Li, J. Current opinions on foam-based hydro-fracturing in deep geological reservoirs. Geomech. Geophys. Geo-Energ. Geo-Resour. 2015, 1, 121-134. [CrossRef]

13. Hoek, E.; Martin, C. Fracture initiation and propagation in intact rock-A review. J. Rock Mech. Geotech. Eng. 2014, 6, 287-300. [CrossRef]

14. Atkinson, B.K. Fracture Mechanics of Rock; Elsevier: Amsterdam, The Netherlands, 2015.

15. Hossain, M.; Rahman, M.; Rahman, S. Hydraulic fracture initiation and propagation: Roles of wellbore trajectory, perforation and stress regimes. J. Pet. Sci. Eng. 2000, 27, 129-149. [CrossRef]

16. Lyu, Q.; Long, X.; Ranjith, P.G.; Tan, J.; Kang, Y. Experimental investigation on the mechanical behaviours of a low-clay shale under water-based fluids. Eng. Geol. 2018, 233, 124-138. [CrossRef]

17. Lyu, Q.; Long, X.; Ranjith, P.G.; Tan, J.; Kang, Y.; Wang, Z. Experimental investigation on the mechanical properties of a low-clay shale with different adsorption times in sub-/super-critical $\mathrm{CO}_{2}$. Energy 2018, 147, 1288-1298. [CrossRef]

18. Czanderna, A.; Rao, C.R.; Honig, J. The anatase-rutile transition. Part $1-$ Kinetics of the transformation of pure anatase. Trans. Faraday Soc. 1958, 54, 1069-1073. [CrossRef]

19. Fredrich, J.T.; Evans, B.; Wong, T.F. Micromechanics of the brittle to plastic transition in carrara marble. J. Geophys. Res. Solid Earth 1989, 94, 4129-4145. [CrossRef]

20. Gibb, F.G. High-temperature, very deep, geological disposal: A safer alternative for high-level radioactive waste? Waste Manag. 1999, 19, 207-211. [CrossRef]

21. Rao, Q.-H.; Wang, Z.; Xie, H.-F.; Xie, Q. Experimental study of mechanical properties of sandstone at high temperature. J. Cent. South Univ. Technol. 2007, 14, 478-483. [CrossRef]

22. Tiab, D.; Donaldson, E.C. Petrophysics: Theory and Practice of Measuring Reservoir Rock and Fluid Transport Properties; Gulf Professional Publishing: Houston, TX, USA, 2011.

23. Dandekar, A.Y. Petroleum Reservoir Rock and Fluid Properties; CRC Press: Boca Raton, FL, USA, 2013.

24. Al-Bazali, T.; Zhang, J.; Chenevert, M.E.; Sharma, M.M. Factors controlling the compressive strength and acoustic properties of shales when interacting with water-based fluids. Int. J. Rock Mech. Min. Sci. 2008, 45, 729-738. [CrossRef]

25. Rathnaweera, T.; Ranjith, P.; Perera, M.; Haque, A.; Lashin, A.; Al Arifi, N.; Chandrasekharam, D.; Yang, S.; $\mathrm{Xu}$, T.; Wang, S. $\mathrm{CO}_{2}$-induced mechanical behaviour of hawkesbury sandstone in the gosford basin: An experimental study. Mater. Sci. Eng. A 2015, 641, 123-137. [CrossRef]

26. Shukla, R.; Ranjith, P.; Choi, S.; Haque, A.; Yellishetty, M.; Hong, L. Mechanical behaviour of reservoir rock under brine saturation. Rock Mech. Rock Eng. 2013, 46, 83-93. [CrossRef]

27. Rathnaweera, T.; Ranjith, P.; Perera, M.; Lashin, A.; Al Arifi, N. Non-linear stress-strain behaviour of reservoir rock under brine saturation: An experimental study. Measurement 2015, 71, 56-72. [CrossRef] 
28. Farquhar, S.; Pearce, J.; Dawson, G.; Golab, A.; Sommacal, S.; Kirste, D.; Biddle, D.; Golding, S. A fresh approach to investigating $\mathrm{CO}_{2}$ storage: Experimental $\mathrm{CO}_{2}$-water-rock interactions in a low-salinity reservoir system. Chem. Geol. 2015, 399, 98-122. [CrossRef]

29. Rathnaweera, T.; Ranjith, P.; Perera, M. Salinity-dependent strength and stress-strain characteristics of reservoir rocks in deep saline aquifers: An experimental study. Fuel 2014, 122, 1-11. [CrossRef]

30. Nasvi, M.; Ranjith, P.; Sanjayan, J.; Haque, A.; Li, X. Mechanical behaviour of wellbore materials saturated in brine water with different salinity levels. Energy 2014, 66, 239-249. [CrossRef]

31. Mohsenzadeh, A.; Al-Wahaibi, Y.; Al-Hajri, R.; Jibril, B. Effects of concentration, salinity and injection scenario of ionic liquids analogue in heavy oil recovery enhancement. J. Pet. Sci. Eng. 2015, 133, 114-122. [CrossRef]

32. ASTM. D3967 Standard test method for splitting tensile strength of intact rock core specimens. In Annual Book of ASTM Standards; American Society for Testing and Materials: West Conshohocken, PA, USA, 2008.

33. Brady, B.H.; Brown, E.T. Rock Mechanics: For Underground Mining; Springer Science \& Business Media: Berlin, Germany, 2013.

34. Khazanehdari, J.; Sothcott, J. Variation in dynamic elastic shear modulus of sandstone upon fluid saturation and substitution. Geophysics 2003, 68, 472-481. [CrossRef]

35. Perera, M.; Ranjith, P.; Peter, M. Effects of saturation medium and pressure on strength parameters of latrobe valley brown coal: Carbon dioxide, water and nitrogen saturations. Energy 2011, 36, 6941-6947. [CrossRef]

36. Dove, P.M. The dissolution kinetics of quartz in sodium chloride solutions at 25 degrees to 300 degrees C. Am. J. Sci. 1994, 294, 665-712. [CrossRef]

37. Min, F.; Peng, C.; Liu, L. Investigation on hydration layers of fine clay mineral particles in different electrolyte aqueous solutions. Powder Technol. 2015, 283, 368-372. [CrossRef]

38. Hueckel, T. Chemo-plasticity of clays subjected to stress and flow of a single contaminant. Int. J. Numer. Anal. Methods Geomech. 1997, 21, 43-72. [CrossRef]

39. Roshan, H.; Oeser, M. A non-isothermal constitutive model for chemically active elastoplastic rocks. Rock Mech. Rock Eng. 2012, 45, 361-374. [CrossRef]

40. Feng, X.-T.; Chen, S.; Zhou, H. Real-time computerized tomography (CT) experiments on sandstone damage evolution during triaxial compression with chemical corrosion. Int. J. Rock Mech. Min. Sci. 2004, 41, 181-192. [CrossRef]

41. Swolfs, H.S. Influence of Pore-Fluid Chemistry and Temperature on Fracture of Sandstone under Confining Pressure; Texas A \& M University: College Station, TX, USA, 1971.

42. Newton, R.C.; Manning, C.E. Quartz solubility in $\mathrm{H}_{2} \mathrm{O}-\mathrm{NaCl}$ and $\mathrm{H}_{2} \mathrm{O}-\mathrm{CO}_{2}$ solutions at deep crust-upper mantle pressures and temperatures: 2-15 kbar and 500-900 C. Geochim. Cosmochim. Acta 2000, 64, 2993-3005. [CrossRef]

43. Thompson, J.G.; Uwins, P.J.; Whittaker, A.K.; Mackinnon, I.D. Structural characterisation of kaolinite: $\mathrm{NaCl}$ intercalate and its derivatives. Clays Clay Miner. 1992, 40, 369-380. [CrossRef]

44. Dyke, C.; Dobereiner, L. Evaluating the strength and deformability of sandstones. Q. J. Eng. Geol. Hydrogeol. 1991, 24, 123-134. [CrossRef]

45. Lockner, D. The Role of Acoustic Emission in the Study of Rock Fracture; International Journal of Rock Mechanics and Mining Sciences \& Geomechanics Abstracts; Elsevier: Amsterdam, The Netherlands, 1993; pp. 883-899.

46. Filipussi, D.; Guzmán, C.; Xargay, H.; Hucailuk, C.; Torres, D. Study of acoustic emission in a compression test of andesite rock. Procedia Mater. Sci. 2015, 9, 292-297. [CrossRef]

47. Wang, S.; Huang, R.; Ni, P.; Pathegama Gamage, R.; Zhang, M. Fracture behavior of intact rock using acoustic emission: Experimental observation and realistic modeling. ASTM Geotech. Test. J. 2013, 36, 903-914. [CrossRef]

48. Masuda, K.; Satoh, T.; Nishizawa, O. Ultrasonic transmission and acoustic emission monitoring of injection-induced fracture processes in rock samples. In Proceedings of the 47th US Rock Mechanics/ Geomechanics Symposium, San Francisco, CA, USA, 23-26 June 2013; American Rock Mechanics Association: New York, NY, USA, 2013. 
49. Wasantha, P.; Ranjith, P.; Shao, S. Energy monitoring and analysis during deformation of bedded-sandstone: Use of acoustic emission. Ultrasonics 2014, 54, 217-226. [CrossRef]

50. Perera, M.; Ranjith, P.; Viete, D. Effects of gaseous and super-critical carbon dioxide saturation on the mechanical properties of bituminous coal from the southern sydney basin. Appl. Energy 2013, 110, 73-81. [CrossRef]

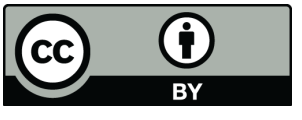

(C) 2018 by the authors. Licensee MDPI, Basel, Switzerland. This article is an open access article distributed under the terms and conditions of the Creative Commons Attribution (CC BY) license (http:/ / creativecommons.org/licenses/by/4.0/). 